\title{
Arbor
}

\section{Premios Nobel}

\author{
Juan Fernández Santarén
}

Arbor CLXXI, 673 (Enero), 87-128 pp.

Todos los años alrededor del 10 de diciembre, aniversario de la muerte de Alfred Nobel, Estocolmo y Oslo se convierten en centro del mayor evento científico y literario: los Premios Nobel, el galardón que recompensa los logros de excelenecia en los campos de la Física, la Química, la Medicina y la Literatura, así como el Premio de la Paz. Se han cumplido ya cien años de su primera concesión y es momento de retrotraernos en el tiempo para recordar algunos rasgos biográficos y personales de Alfred Nobel, su fundador. Y es momento igualmente de evocar la compleja y dificil andadura que hubo que recorrer para dar forma legal a las ideas que Nobel habia expresado en su testamento, organizar la Fundación Nobel y a partir de ahí, iniciar la concesión de los premios.

\section{ALFRED NOBEL: Una semblanza biográfica}

Los Nobel son descendientes de granjeros escandinavos y el nombre, que inicialmente fue Nobelius, toma su origen de un lugar llamado Nöbbelóv en la provincia de Scania, al sur de Suecia. Dicho nombre fue asumido, según tradición del siglo XVII, por el primer miembro de la familia que alcanzó educación universitaria, un tal Petrus Olofsson, nacido en 1655 en Nöbbelöv quien se registró en la Universidad sueca de Uppsala con el nombre de Petrus Olav Nobelius. Este hombre, especialmente dotado para la música, completó su educación en leyes y su talento le llevó a contactar con Olof Rudbeck, famoso magistrado y líder intelectual de la Universidad a quien pidió la mano de su hija Vendela. De esta unión descienden los Nobel. 
La familia, aunque se introdujo en los círculos de influencia no prosperó y el hijo de Petrus y Vendela fue un artista cuyos ingresos no se ajustaban con su estandar de vida. El nieto mas joven, Immanuel Sr., que tenía solamente tres años cuando falleció su padre, inició los estudios de medicina pero no tuvo oportunidad de terminarlos. Como cirujano militar acortó su nombre académico cambiándolo a Nobel.

$\mathrm{Su}$ hijo, Immanuel Jr., nacido en Gävle en 1801, fue el padre de Alfred Nobel y una personalidad digna de mención. Inventor genial y con una vitalidad inusual no tuvo ninguna educación en la escuela ni conocía ningún idioma extranjero. Prácticamente fue un autodidacta, pero lleno de ideas que indicaban un grado inusual de inteligencia. Aprendiz de un constructor a los 18 años, inicialmente en Gävle y posteriormente en Estocolmo, asistió a las únicas escuelas existentes entonces en la capital, la Escuela de Arquitectura de la Academia de Arte y la denominada Escuela Mecánica. En 1837 se trasladó a Finlandia y posteriormente a Rusia donde se estableció como ingeniero en St. Petersburgo. Aunque Immanuel Nobel fabricó diferentes tipos de herramientas su interés pronto derivó hacia las minas explosivas.

Ante la inminente guerra de Crimea el gobierno ruso ayudo a Nobel con un subsidio para ampliar su factoría y cuando por fin estalló la guerra en 1854, la Alta Comandancia le confió el programa de fabricación y colocación de minas. Immanuel Nobel rindió de esta forma un gran servicio al gobierno, motivo por el cual fue galardonado con la medalla de oro Imperial en 1853 a pesar de su condición de extranjero.

Pero la guerra de Crimea acabó en derrota y los talleres de Nobel fueron a la quiebra. Hundido y desengañado, regreso a Estocolmo en 1859 casi tan pobre como cuando, veinte años atrás, había abandonado las costas de Suecia.

Los tres hijos de Immanuel Nobel fueron importantes. El mayor, Robert desarrolló la industria del petróleo en Baku, el segundo, Ludvig, fundó una factoría de armas en St. Petersburgo y también participó en las finanzas de la organización de Baku. El tercer hijo fue Alfred Nobel, que nació en Estocolmo el 21 de Octubre de 1833.

Curiosamente, Alfred nunca fue a la escuela, si exceptuamos que a la edad de 8 años cursó el primer grado elemental en su parroquia donde permaneció solo un año. Después la familia se trasladó a St. Petersburgo donde los tres hermanos, Robert, Ludwig y Alfred, recibieron instrucción de un tutor privado. Alfred tampoco fue a la Universidad, y al igual que su padre puede considerársele como un autodidacta, porque su educación tutorial terminó en 1850 , cuando sólo tenía 16 años. No obstante su madurez intelectual era muy superior a la de los muchachos de su 


\section{Premios Nobel}

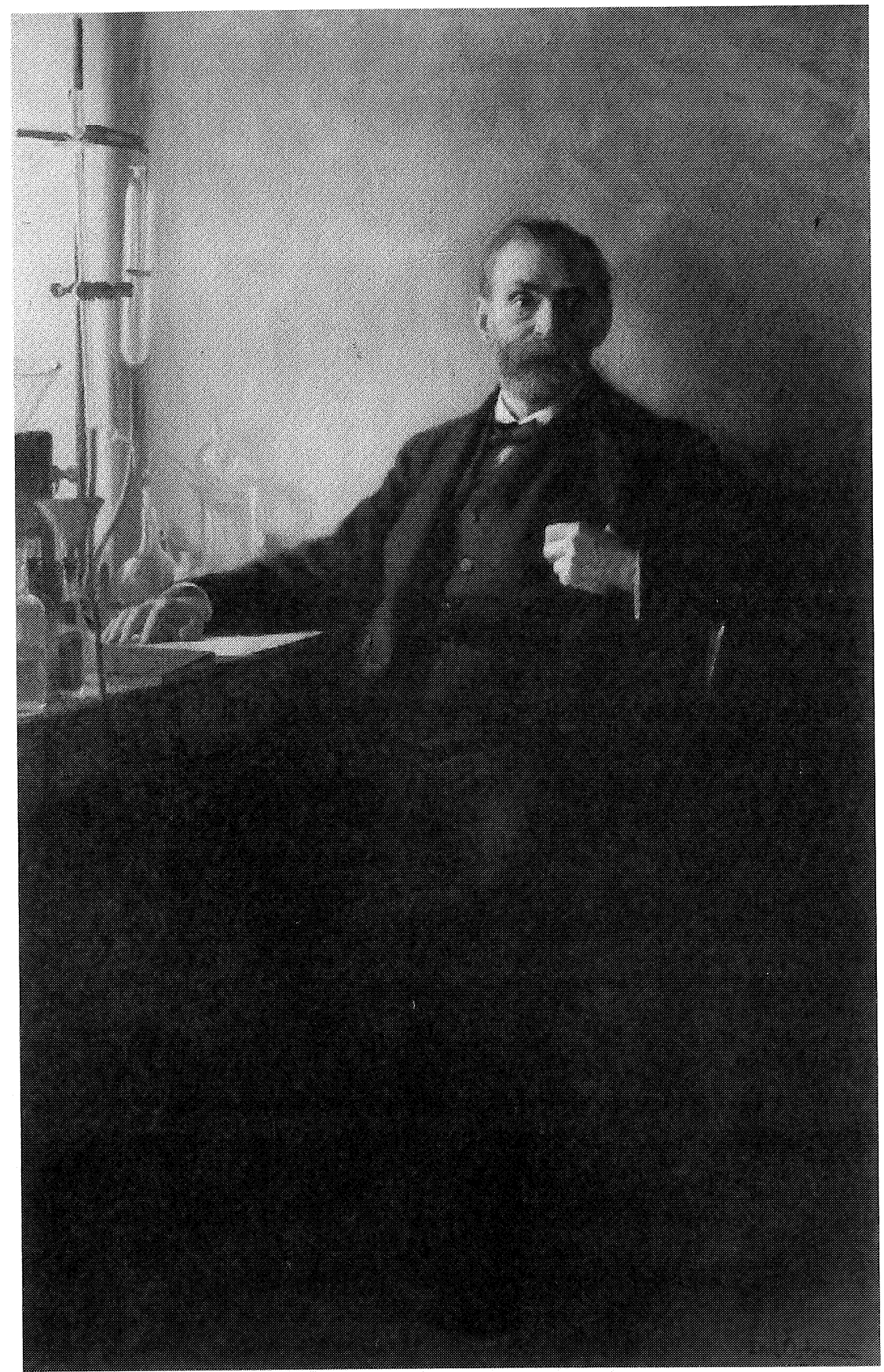

Alfred Nobel.

Cuadro de Emil Osterman pintado en 1915. 


\section{Juan Fernández Santarén}

edad. Se entrenó en química, sabía alemán, inglés y francés además de sueco y ruso. También mostró un gran interés por la literatura, especialmente la inglesa.

En aquella época la situación financiera de su padre era buena lo que le permitió mejorar su educación incluyendo un crucero de dos años, en parte también con objeto de mejorar su delicada salud, que le llevó hasta América aunque la mayoría del tiempo vivió en París donde continuó sus estudios de química en diversos laboratorios. A su vuelta ingresó en una de las fábricas de su padre y allí permaneció hasta la bancarrota de 1859. Pronto comenzó a experimentar con la nitroglicerina, un compuesto con alto riesgo de explosión que el italiano Ascanio Sobrero había descubierto en 1847 pero cuyo manejo seguía siendo un problema técnico sin resolver 18 años después de su invención. Alfred Nobel tuvo éxito precisamente al conseguir detonarlo de manera controlada. La primera explosión la llevó a cabo en Rusia, en mayo de 1862. En aquella ocasión, colocó nitroglicerina en un tubo de cristal firmemente cerrado en el interior de un recipiente de metal lleno con pólvora negra que prendió por medio de una mecha. El conjunto, sumergido en un canal, causó una gran explosión bajo el agua. Al año siguiente, Alfred Nobel recibió la primera patente rusa de su nueva técnica de explosión.

Ese mismo año Alfred fue a Estocolmo para unirse a su padre en el trabajo con la nitroglicerina. Immanuel Nobel creía que había descubierto una pólvora nueva y mas potente y pidió a su hijo que regresara a casa y le ayudara a desarrollarla. Aunque el presunto descubrimiento resultó carente de valor práctico, Alfred se quedó allí e instaló una pequeña planta en Heleneborg cerca de Estocolmo para la fabricación de nitroglicerina. Aquí repitió sus experimentos de Rusia pero invirtiendo el orden de los componentes. En lugar de colocar un tubo de nitroglicerina dentro de un recipiente lleno con pólvora, introdujo un pequeño tubo de pólvora, provisto de una mecha en un gran tubo repleto de nitroglicerina. El resultado fue excelente. Al encender la pólvora negra por medio de la mecha, la nitroglicerina explotó. Se había descubierto el «Detonador» Nobel, el mayor invento de Alfred que revolucionó de forma espectacular la técnica de los explosivos y su subsiguiente desarrollo industrial.

Las compañías ferroviarias y mineras se dieron cuenta de las posibilidades de la nueva patente de Nobel y comenzaron a utilizarla inmediatamente. Ya en 1864 se empleó para abrir el túnel bajo la isla de Södermalm, al sur de Estocolmo, permitiendo el acceso del tren hasta la capital

No obstante, la producción tuvo unos comienzos difíciles. El primer accidente serio ocurrió en Suecia, el 3 de Septiembre de 1864, cuando la pequeña factoría de Heleneborg voló por los aires. Se perdieron varias vi- 
das y entre las víctimas se encontraba Emil, el hermano pequeño de $\mathrm{Al}$ fred Nobel. Este desastre destrozó al anciano padre quien unas semanas mas tarde sufrió una crisis de la que, aunque se recuperó parcialmente, nunca pudo recobrar totalmente sus facultades físicas y mentales, y en 1872 murió. No fue el único accidente. En Panamá, San Francisco, Australia, Alemania y Bélgica ocurrieron explosiones devastadoras similares que cuestionaron el gran descubrimiento en el campo de los explosivos. La opinión mundial estaba perturbada a consecuencia de los numerosos accidentes y las autoridades de la ciudad de Estocolmo declararon, tras el suceso de Heleneborg, que si Alfred Nobel quería seguir con la experimentación debía hacerlo en una barcaza anclada en el Lago Mälaren y llevarla a cabo el mismo. Y Alfred Nobel lo hizo.

Durante el tenebroso periodo que siguió al accidente Alfred Nobel nunca perdió la confianza aunque lógicamente nadie estaba interesado en invertir dinero en una empresa tan arriesgada como la fabricación de nitroglicerina. Sin embargo, a finales de 1864, J. W. Smitt, un millonario de Estocolmo asumió la responsabilidad económica de la empresa de Nobel cuando éste levanto nuevamente una fábrica en tierra firme, en Vinterviken, cerca de Estocolmo. A comienzos de 1865 Alfred controlaba la dirección de todo lo concerniente a las pruebas, producción y explotación del nuevo explosivo en Suecia. Pronto inició sus viajes al extranjero para obtener mas patentes y para crear compañías para su producción y aunque tuvo que salvar numerosos obstáculos, al cabo de pocos años había creado una poderosa industria para la manufacturación de nitroglicerina.

Simultáneamente Alfred Nobel experimentaba, de manera exhaustiva, con objeto de hacer que la nitroglicerina fuese menos peligrosa. Sus esfuerzos condujeron finalmente al descubrimiento de la dinamita, aceite explosivo adsorbido en tierra de diatomeas, un material fácil de obtener que podía manejarse con mas seguridad, empaquetarse en forma de cartuchos, transportarse y almacenarse sin riesgo. En 1867 patentaba en Suecia, este segundo gran descubrimiento que en combinación con el detonador anteriormente mencionado proporcionaba por primera vez una técnica racional para el manejo de explosivos. En 1868 Immanuel y Alfred Nobel fueron conjuntamente galardonados con el Premio Letterstedt de la Academia Sueca de Ciencias, un honor que Alfred recordó durante toda su vida. Fue su Premio Nobel.

A partir de ese momento la situación cambió. Lo que durante 18 años había sido simplemente una curiosidad química que entrañaba grandes peligros para la humanidad, se había transformado, gracias al trabajo de la familia Nobel, en uno de los factores mas condicionantes de la época, 


\section{Juan Fernández Santarén}

posibilitando el minado de estructuras que antes eran inexpugnables y permitiendo, por ejemplo, la fácil construcción de túneles y canales.

Alfred Nobel se vio obligado a partir de entonces a invertir gran parte de su tiempo en continuos viajes para establecer y supervisar las fábricas y para proteger sus derechos de patente. Ahora hacía uso de su educación cosmopolita y de su sólido conocimiento de idiomas. Durante los años 1867 a 1874 la producción mundial de dinamita pasó de 11 a 3120 toneladas/año.

A pesar de todas esas actividades, en 1875 logró un nuevo descubrimiento. Fue la "gelatina explosiva», también llamada «dinamita de caucho", en la que un pequeño porcentaje de celulosa o colodión bajamente nitrados se disolvían en nitroglicerina formando una masa viscosa semisólida. La mezcla no era tan voluminosa como la dinamita, tenía mayor poder explosivo y se consumía totalmente en la ignición.

La siguiente patente fue un explosivo sin humo, la «Ballistite» 0 «explosivo Nobel», en el que nitroglicerina y nitrocelulosa se mezclaba a partes iguales obteniéndose una sustancia rojiza que podía pulverizarse. A diferencia de la «gelatina»su explosión resultaba menos violenta y permitía desarrollar una fuerza balística propulsora capaz de utilizarse en las armas de fuego sin provocar la explosión del continente. Se había logrado aminorar el poder explosivo de la nitroglicerina. Este invento, realizado en 1887, tuvo posteriormente una gran importancia en el avance de la fabricación de munición para armas de fuego.

El progreso de las industrias Nobel fue imparable aunque no abarcó a toda Europa. En Inglaterra, por ejemplo, Nobel no tuvo éxito en sus intentos para obtener la licencia de fabricante. En parte fue debido al prejuicio de los británicos ante cualquier empresa creada por iniciativa extranjera, aunque el obstáculo principal, e insalvable, fue Sir Frederick Abel, consejero de la Cámara de los Comunes en materia de explosivos, quien ejerció una influencia decisiva por mantener la nitroglicerina de Nobel lejos de Inglaterra. En 1869 se introdujo el «Acta de la Nitroglicerina» en la que se prohibía la importación, almacenamiento y transporte de dicha substancia en el país.

Nobel tuvo serios problemas con el físico James Dewar y Sir Frederick Abel antes aludido. El episodio merece un comentario. En su intento por introducir la «Ballistite» en Inglaterra, Nobel fue requerido por una comisión del gobierno británico, de la que formaban parte Dewar y Abel, para dar todos los detalles sobre la fabricación de su explosivo. Nobel los dio y el resultado fue que Dewar y Abel introdujeron mínimos cambios y patentaron por su cuenta el producto con el nombre de «Cordita». Nobel se sintió engañado y no dudó en emprender acciones legales. 


\section{Premios Nobel}

En la base de la querella Nobel hablaba de «nitrocelulosa soluble» mientras que la defensa alegó que sus defendidos habían utilizado «la variedad insoluble de la nitrocelulosa». Nobel perdió el caso que además le costó 30.000 libras y redujo casi a cero el valor de la patente de la «Balistita». A su regreso a París intentó recrear la historia escribiendo «The Patent Bacillus» en donde se burlaba del sistema de cortes británico. Posteriormente y con objeto de aminorar la injusticia, Nobel llegó a cobrar derechos por la fabricación de «Cordita», en una cantidad que ascendía a la mitad de lo que percibía por kilo de «Ballistite».

A pesar del enorme uso de la dinamita en el Nuevo Mundo tampoco Alfred Nobel sacó excesivos beneficios de ello. Sus luchas contra los poco escrupulosos financieros, en las que perdió mucho tiempo, le dieron demasiados disgustos y Nobel perdió todo su interés en los negocios americanos. Después de 1866 ya no cruzó el Atlántico y no intercambió mas de un par de cartas con las dos grandes compañías que fabricaban dinamita allí.

Un capítulo interesante de la historia de la familia Nobel es el papel desempeñado por Robert quien también aprendió a fabricar nitroglicerina con la idea de introducir dicho producto en Finlandia. No obstante, durante un viaje a Caucasia realizado por encargo de su hermano Ludwig se quedo impresionado por las grandes posibilidades que ofrecía la explotación del Nafta Ruso, que en cantidades ilimitadas fluía de la tierra en las proximidades de Baku. Este fue el comienzo de la industria del petróleo de la familia Nobel.

Dos años mas tarde regresó y comenzó a extraer petróleo. Los conocimientos de ingeniería y el talento de la familia dieron sus frutos. En un corto espacio de tiempo los hermanos Robert y Ludwig Nobel crearon una industria a nivel mundial, la Nobel Oil Company, en la que Alfred Nobel también participó a partir de 1878.

\section{La Personalidad de Alfred Nobel}

Probablemente pocos nombres suecos sean más conocidos mundialmente que el de Alfred Nobel, aunque no mucha gente sabe realmente algo de él. Quizá se recuerda que fue un gran inventor, pero exactamente de qué, además de la dinamita, permanece en la penumbra. También se sabe lógicamente que instituyó un gran premio. Pero de su carácter personal, de su manera de pensar, difícilmente el gran publico tiene una idea. En los altos círculos industriales y financieros de París, Londres, Berlín y Viena, las actividades de Nobel eran bien conocidas y respetadas, pero el era casi un desconocido, sobre todo si lo comparamos con los 


\section{Juan Fernández Santarén}

otros dos genios suecos contemporáneos, el Capitán John Ericsson y Gustaf Patrik de Laval. Señalemos por ejemplo que el único cuadro que hay de el se pintó casi 20 años después de su muerte. Se ha llegado a calificar a Nobel como «el hombre que nadie conocía» y aunque algo exagerado el apelativo tiene su lógica. Alfred Nobel fue un hombre de exquisita educación, idealista, pero tremendamente retraído y enemigo de cualquier tipo de publicidad. Cuando en cierta ocasión su hermano Ludwig le pidió información biográfica sobre su padre y sobre el propio Alfred, la respuesta de éste no pudo ser mas contundente:

"¿Por qué quieres atormentarme con ensayos biográficos? Nadie lee biografías salvo si son de actores o de asesinos. Tengo muchas cosas importantes que pasan semanas, incluso meses en mi escritorio por falta de tiempo. En estas circunstancias me resulta imposible escribir biografias a. menos que tengan la brevedad de una descripción policiaca, aunque realmente creo que esas son las mas elocuentes. Por ejemplo, Alfred Nobel, una pobre criatura medio viva. Sus mayores méritos: tener las uñas limpias y no ser nunca una carga para nadie. Los mayores defectos: no tener una familia, buen humor y buen estómago. Su mayor y única petición: no ser enterrado vivo. Hechos importantes de su vida: ninguno».

Nobel tenía una marcada tendencia a no permitir que nadie estuviese demasiado cerca de el y sus allegados cuentan que durante prolongados periodos desaparecía y nadie sabía donde estaba. Era la época en la que, usando sus propias palabras el «espíritu de Niflheim» le invadía y sentía la necesidad de estar sólo. Y aquí nos encontramos con una de las muchas contradicciones internas de la vida mental y emocional de Alfred Nobel. En efecto, su carácter le conducía con frecuencia a serias discrepancias entre su visión teórica de las cosas y su modo de actuar. Hombre retraído, prácticamente inaccesible como acabamos de señalar, pero que con frecuencia se queja y lamenta su soledad y la ausencia de verdaderos amigos. Se puede leer en una de sus cartas:

«Haces referencia a mis muchos amigos, ¿Donde están? ¿En el cenagoso fondo de las ilusiones perdidas, o escuchando atareadamente el sonido de los peniques? Créeme, uno sólo tiene amigos entre los perros a los que da de comer o entre los gusanos que uno alimenta con los propios gusanos».

Particularmente tras la muerte de su madre, acaecida 1889, Alfred Nobel sintió a menudo la imperiosa necesidad de contar con algún amigo íntimo al que poder recurrir. En aquella época escribe:

«Durante los pasados nueve días he estado enfermo obligado a permanecer encerrado en casa sin otra compañía que el ayuda de cámara que tengo a 
sueldo; nadie ha preguntado por mi. Me parece que durante este tiempo he estado mucho peor que lo que Bouté (su médico) cree. El dolor es muy persistente. Además mi corazón se ha vuelto tan pesado que parece de plomo. Cuando con 54 años uno se siente tan solo en el mundo y un sirviente de pago es la única persona que me muestra cierta amabilidad, entonces afloran pesados pensamientos, mucho mas pesados que lo que la gente imagina. Puedo ver en los ojos de mi sirviente cuanta compasión me tiene, aunque yo no puedo, desde luego, permitir que el lo note».

Nobel nunca tuvo éxito social, aunque curiosamente reunía todas las cualidades para ello. A su soledad contribuyó, sin duda, el hecho de no tener un hogar ya que nunca se estableció realmente en ninguna parte y siempre se definió como un extranjero en todos los países en los que vivió mas o menos temporalmente. Cuando inició sus actividades industriales, se instaló en Krümmel, cerca de Hamburgo, aunque permanecía mas tiempo en el laboratorio que en casa y sobre todo en compartimentos de trenes, camarotes de barcos y hoteles. En 1875 compró una casa en la Avenida Malakoff de París, pero cuando el laboratorio de allí se quedó pequeño, construyó una nueva casa en Sévran, a las afueras de la capital francesa. Tampoco echó raíces allí y en 1890 se traslado a Italia donde compró una villa en San Remo, «Mio Nido». Por último, al final de su vida intentó establecer un hogar en Suecia donde presumiblemente esperar al final de sus días, pero no lo logró.

Si bien es cierto que numerosas experiencias amargas hicieron de Nobel un escéptico receloso, fue un hombre generoso cuyas ayudas siempre estuvieron inspiradas por un sentimiento religioso, aunque para el la religión tenía valor solamente como expresión de su propio amor a la humanidad. Fue recordado por muchos como un hombre ateo y enemigo de todo culto religioso aunque convendría aclarar que profesó un tipo especial de ateísmo influenciado profundamente por las lecturas de juventud de la obra de Shelley. Nobel rechazaba el concepto del Dios que preside todos los hechos religiosos del día, porque este Dios le parecía cruel e injusto ya que había originado todas las guerras y persecuciones religiosas. Pero detrás de esta negativa podía verse claramente su predisposición a aceptar un Dios de paz y amor universal hacia el hombre, de manera que en realidad el ateísmo de Shelley y Nobel se aproximan mucho al cristianismo y platonismo.

Tampoco sus convicciones políticas fueron tan radicales como se supone. No hay duda que recibió cierta influencia del nihilismo soviético, que impregnaba el ambiente durante su juventud, y que se opuso al absolutismo dictatorial del Zar, pero por encima de todo, en su primera época, fue un anarquista. Entre sus papeles se ha encontrado el comienzo de 
una novela en la que uno de los personajes con el significativo nombre de Mr. Avenir (Mr. Futuro) expone el propio programa político de Alfred Nobel. «En verdad», declara Avenir, «en el mundo solo hay tres formas de gobierno: autocracia hereditaria, monarquía constitucional y república. Las tres son igual de malas».

En su madurez Nobel se consideraba como un Social Demócrata o al menos así se describía aunque «moderado». En la práctica hay que admitir que tanto sus principios como sus acciones se alejaban bastante de la social democracia. Personalmente se mantenía muy distante de los trabajadores de las industrias que controlaba, en marcado contraste con la política de su hermano Ludvig que mostraba gran interés en las condiciones de vida de sus empleados. Con sus sirvientes personales fue mas generoso aunque insistiendo siempre en el estricto cumplimiento de la etiqueta y no permitiendo nunca ninguna familiaridad.

Siendo un intelectual fuertemente influenciado por las tendencias humanísticas de la literatura contemporánea y con una aguda visión sobre los sistemas políticos de su tiempo, Alfred Nobel no pudo evitar el implicarse en las discusiones sobre la guerra y la paz. Al igual que Shelley fue un completo pacifista, pero en relación con los métodos para evitar la guerra fue bastante escéptico. Cuando se le pedía ayuda para apoyar el desarme y la paz en el mundo normalmente la daba pero declarando que tenia la misma utilidad que el tirar el dinero por una ventana. Tampoco creía, según sus escritos, en la posibilidad de un desarme general y nunca asistió a ningún congreso de paz. Sin embargo tenia un sincero interés por que se pudiera alcanzar una paz permanente y en 1893, es decir dos años antes de su último testamento, escribió una carta a Bertha Kinsky en la que se refleja su propio programa de paz. De acuerdo con Nobel, la única forma efectiva de prevenir la guerra era lograr un acuerdo entre países para que todos combatieran juntos contra la nación que primero violara la paz. Escribió lo siguiente:

«Estoy dispuesto a dar una parte de mi fortuna para crear un premio que se otorgaría cada cinco años, digamos seis veces, porque si en treinta años no ha sido posible reformar el actual sistema estamos abocados irremediablemente a regresar al barbarismo. Este premio debería concederse al hombre o mujer que indujese a Europa a dar el primer paso hacia la idea general de paz. No me refiero al desarme, que sólo se podrá alcanzar muy lentamente. Pero debería ser relativamente fácil lograr la idea de que todos los países estuviesen dispuestos a luchar contra el primer agresor. Esto haría la guerra imposible. Incluso las naciones mas guerreras se verían obligadas a permanecer tranquilas. Si la Triple Alianza, en lugar de incluir sólo tres países, incluyese a todos, la paz estaría garantizada por siglos». 


\section{Premios Nobel}

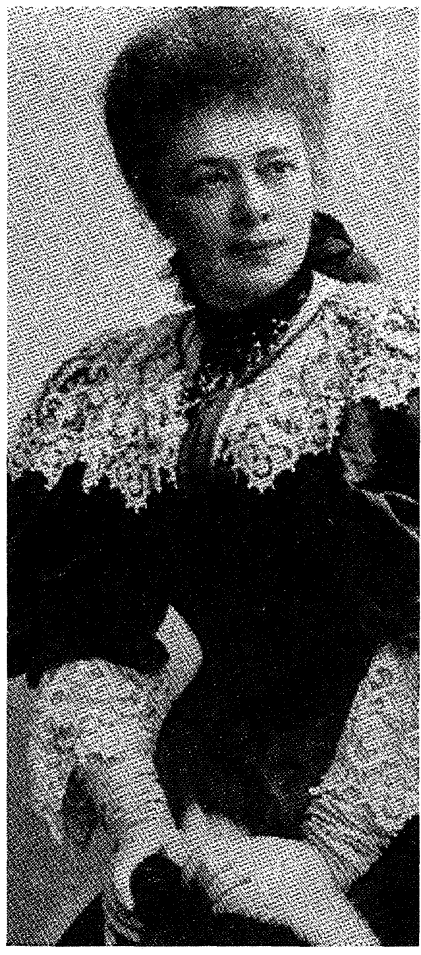

Bertha Kinsky von Chinic

Otra aparente contradicción entre las teorías y la actuación personal de Nobel hace referencia a lo difícil que resulta explicar su interés en los movimientos pacifistas al tiempo que trataba de mejorar diversos tipos de material de guerra. En este sentido casi siempre han sido minusvalorados los logros de Nobel como inventor y sus contribuciones para el desarrollo y mejora de las comunicaciones con la invención de los explosivos modernos. A veces se tiene la idea de que la fortuna de Nobel se basaba en la producción de armamento y no es correcto. La mayor parte de su fortuna, mas del $90 \%$, procedía de los inventos del campo meramente cívico, que equivale a decir fabricación de nitroglicerina con uso práctico.

El interés fundamental de Nobel fue, sin embargo, literario y científico. Tenía, de hecho un marcado y profundo sentimiento de poeta y un considerable poder de imaginación. Sus primeros poemas, escritos en inglés antes de cumplir veinte años, son realmente buenos y aunque también muestran claramente la influencia de Shelley, reflejan su personalidad y hacen aflorar su melancolía, su temperamento sensible y su obsesión religiosa. Posteriormente se embarcó en su carrera científica y empresarial, lo que naturalmente le alejó de la literatura. Cuando pocos años antes de su muerte quiso retornar a ella era demasiado tarde. Su imaginación ya no era tan fuerte como a sus veinte años y el uso de las palabras se había hecho mas vago e incierto. Pero conservó su amor por el arte de la escritura y a pesar de sus ocupaciones, siempre se mantuvo al corriente del desarrollo literario.

Otra fuente de ocupación fue la ciencia, y por encima de todas las ciencias naturales porque, de acuerdo a sus convicciones, era la conquista de éstas la que proporcionaría la felicidad a las futuras generaciones. «Divulgar el conocimiento» escribió «es divulgar el sentimiento de bienestar. Y cuando hablo de bienestar no me refiero a la prosperidad individual. Hablo de la desaparición de una gran parte de los males que venimos heredando desde las épocas oscuras de la humanidad. El avance en la investigación científica irá aumentando su radio de acción y debemos esperar que los microbios, tanto los del ambiente como los del cuer- 


\section{Juan Fernández Santarén}

po, desaparezcan gradualmente y que la única guerra que la humanidad tenga que librar en el futuro sea contra esos microbios».

Alfred Nobel nunca se casó. Tuvo dificultad para encontrar una compañera de su nivel intelectual e incluso no pudo disponer de una secretaria capaz de dominar los idiomas con la suficiente perfección como para satisfacer su demanda. En este punto es digno de mención que en la primavera de 1876 puso un anuncio en un periódico de Viena en el que podía leerse: «hombre sano, caballero altamente educado, viviendo en París, busca una mujer madura con conocimiento de idiomas para actuar como secretaria y ayuda de casa».

$\mathrm{El}$ anuncio fue contestado por Bertha Kinsky von Chinic una mujer de treinta y tres años que se encontraba empleada como institutriz de una ilustre familia de la aristocracia austríaca y que se había enamorado del hijo de la casa, Arthur von Suttner, siete años menor que ella. Cuando los padres se enteraron de la situación se opusieron al matrimonio por la baja clase de la familia Kinsky, razón por la que Bertha respondió al anuncio ofrecido por Nobel, con quien curiosamente apenas estuvo una semana. A juzgar por sus fotografías, Bertha Kinsky era de una belleza radiante y dominaba el inglés, francés e italiano además del alemán nativo. Nobel le preguntó si estaba sentimentalmente comprometida y ella le contó su secreto con el varón von Suttner. Nobel le dijo que había actuado con decisión y que el tiempo se encargaría de borrar su recuerdo, pero a los pocos días Nobel tuvo que marcharse de viaje y dejarla sola en París. En ese tiempo Bertha Kinsky recibía cartas diarias de Arthur von Suttner implorándola que volviera. Y volvió. Abandonó París explicando en una carta a Nobel los motivos de su decisión y regresó a Viena donde se casó en secreto con el varón y se marcharon a vivir al Caúcaso.

Para Nobel la marcha de su secretaria debió ser una experiencia amarga y dolorosa. Posiblemente buscaba en ella a la compañera que le diera la atmósfera que necesitaba en su casa. Once años mas tarde volvió a encontrarse con Bertha y con su marido cuando estos visitaron París aunque en el intermedio mantuvieron frecuente correspondencia. Durante los últimos diez años de su vida, cuando estaba mas comprometido con los movimientos pacifistas, la correspondencia aumentó y Bertha Kinsky ejerció a través de ella una fuerte influencia en la forma final del testamento de Nobel y particularmente en la idea de instituir un Premio de la Paz.

\section{El Testamento de Alfred Nobel y la liquidación de su herencia}

Durante los últimos quince años de su vida Nobel estuvo sometido a numerosas tribulaciones físicas y mentales que le fueron agotando pro- 


\section{Textament}

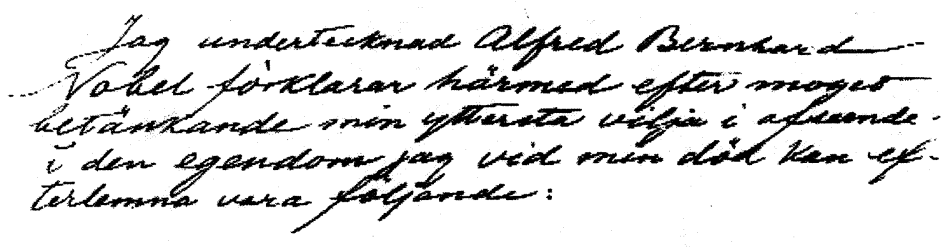

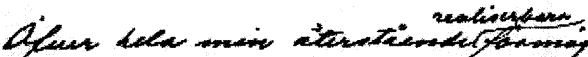

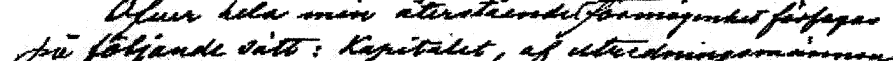

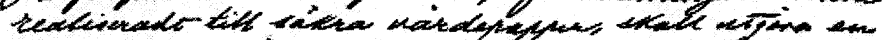

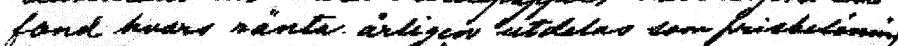

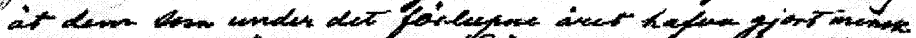

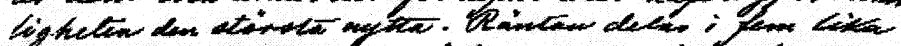

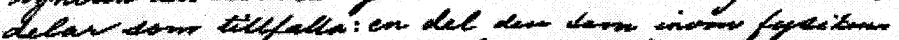

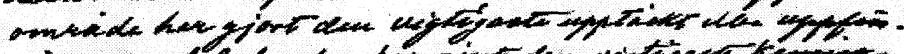

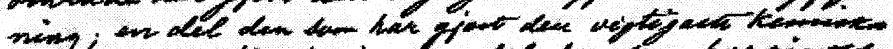

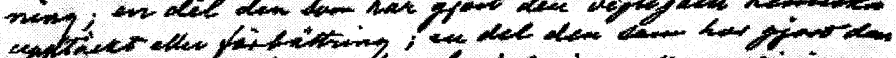

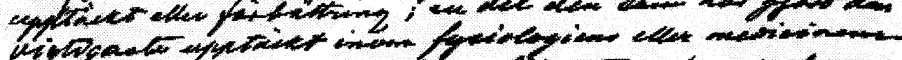

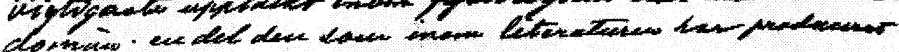

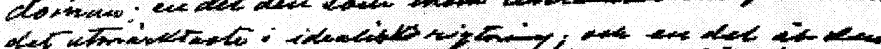

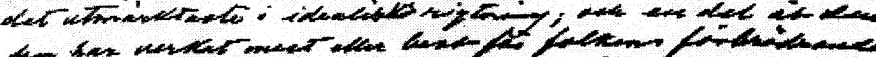

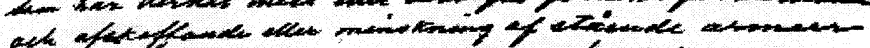
ath of P.

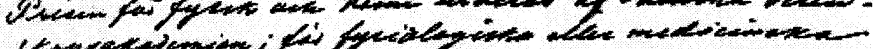

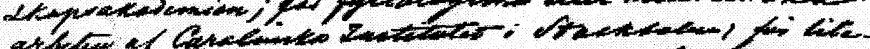

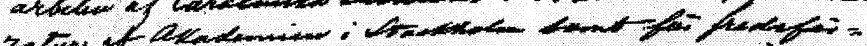

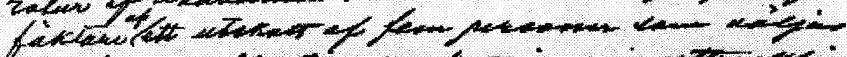

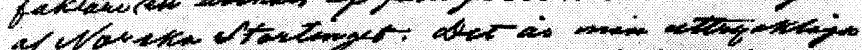

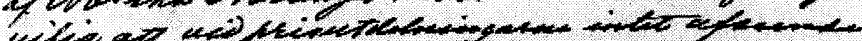

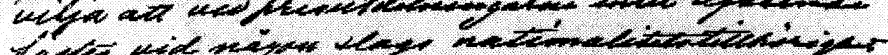

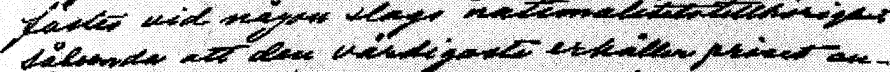

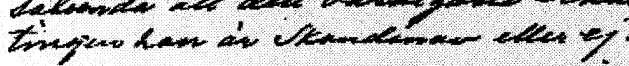

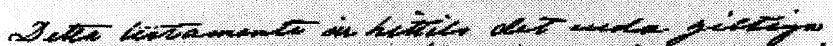

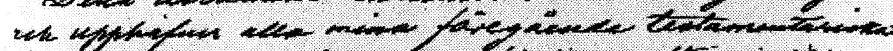

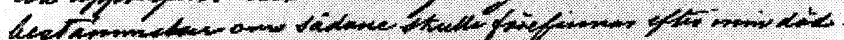

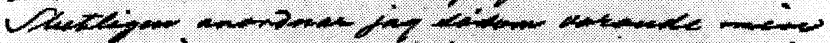

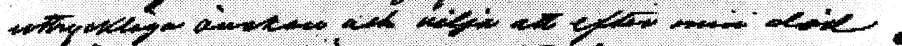

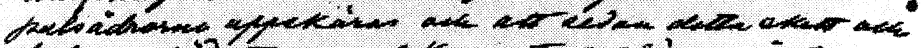

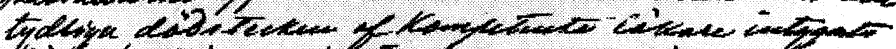

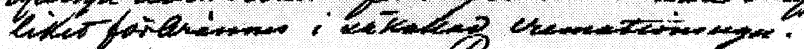

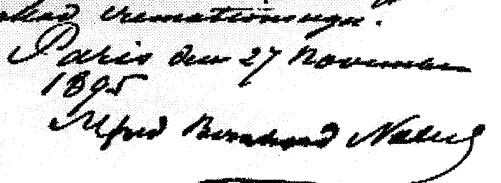

Original del testamento de Alfred Nobel de 1895. 
gresivamente a la vez que le iban conduciendo a una profunda depresión y sensación de soledad como queda reflejado en la correspondencia privada de esa época. A ello contribuyó, de forma decisiva, la muerte de dos miembros de su familia a los que estaba particularmente unido. El 12 de abril de 1888 falleció su hermano mayor Ludvig y el 7 de diciembre de 1889 su madre.

En el otoño de 1895 Nobel paso dos meses en París y sintió que había llegado la hora de escribir su testamento final en el que repartir su fortuna de 33 millones de coronas suecas. El documento tiene fecha de 27 de noviembre de 1895 y esta escrito de puño y letra por el propio Nobel y sin ayuda de ningún abogado dada la aversión que sentía por ellos. La firma final se produjo uno de los primeros días de diciembre en el Swedish Club de París en presencia de cuatro testigos de nacionalidad sueca. Fueron estos: Thorsten Nordenfelt, fabricante de municiones, Sigurd Ehrenborg, oficial retirado de la armada, R. V. Strehlenert y Leonard Hvass dos jóvenes ingenieros. Testigos que en el momento de la firma le oyeron decir:

"Creo que heredar un capital es una desgracia que sólo sirve para causar estupor a la humanidad. Una persona que logra una gran fortuna debe dejar solo una pequeña parte de ella a sus allegados»

El famoso texto del testamento es el siguiente:

La totalidad del resto de mi herencia se repartirá de la siguiente manera:

El capital se invertirá por mis albaceas de forma segura y constituirá una Fundación, cuyos intereses se distribuirán anualmente en forma de premios a aquellos quienes, durante el año precedente, hayan conferido el mayor beneficio a la humanidad. Los intereses se dividirán en cinco partes iguales, que se repartirán de la siguiente forma: una parte a la persona que haya hecho el descubrimiento o invento mas importante dentro del campo de la física; una parte a la persona que haya hecho el descubrimiento o mejora mas importante en química; una parte a la persona que haya hecho el descubrimiento mas importante dentro del dominio de la fisiología o medicina; una parte a la persona que haya producido el trabajo mas destacado de tendencia idealista en el campo de la literatura; y una parte a la persona que haya hecho mas y mejor trabajo por la fraternidad entre naciones, por la abolición o reducción de las armas y el mantenimiento y promoción de la paz.

Los premios de física y química serán concedidos por la Academia Sueca de Ciencias; el de fisiología o medicina por el Instituto Carolino de Estocolmo; el de literatura por la Academia de Estocolmo; y el de la defensa de la paz por un comité de cinco personas elegidas por el Parlamento No- 
ruego. Es mi expreso deseo que en la concesión de los premios no se tengan en cuenta las nacionalidades de los candidatos, de forma que el mas digno sea el que reciba el premio, sea escandinavo o no.

París, 27 de Noviembre de 1895 ALFRED BERNHARD NOBEL

Con este testamento Nobel cancelaba «todas las dotaciones testamentarias previas» en caso de que se encontraran después de su muerte. No se han conservado dichas dotaciones excepto una, fechada el 14 de marzo de 1893, en la cual la Real Academia Sueca de Ciencias era designada como la principal depositaria del legado.

Las horas finales de Nobel fueron trágicas. Las quejas que había expresado en varias de sus cartas quedaron plenamente justificadas: los últimos días estuvo acompañado solamente por sus sirvientes franceses sin tener, como el había soñado, cerca de él

«ningún amigo intimo o pariente cuya mano amable cierre mis ojos y sea capaz de susurrarme al oido alguna palabra amable y sincera de alivio».

Cuando se sintió indispuesto en el estudio de su residencia italiana fue trasladado por sus sirvientes al dormitorio de la segunda planta. Avisaron a un médico que una vez percatado de la gravedad de la situación le prescribió reposo absoluto, recomendación que fue difícil de cumplir porque el paciente sufrió fuertes ataques de agitación. Parece que perdió la capacidad de hablar y la memoria de todas las lenguas excepto la de su infancia. Su viejo sirviente, Auguste, dijo mas tarde que Nobel había empleado en sus últimas horas de vida una serie de palabras ininteligibles para ellos aunque les pareció entender que quería telegrafiar. Así, el 8 de diciembre de 1896 Auguste envió telegramas a Hjalmar el primogénito de su hermano Robert, a Emanuel, el hijo mayor de su hermano Ludvig, quien como sucesor de su padre, era entonces director de la Nobel Brothers Naphtha Company en Baku, y a Ragnar Sohlman el asistente personal de Alfred Nobel de los últimos años. Los tres decidieron viajar a San Remo donde se encontraron el 10 de diciembre, pero ya demasiado tarde para encontrar a Alfred Nobel con vida quien había acabado sus días sólo, tal como había vivido.

Como familiar mayor Emanuel Nobel se hizo cargo de todos los preparativos del funeral. Se decidió que tras una sencilla ceremonia en la villa se repatriasen los restos para llevar a cabo un funeral público que 
finalmente tuvo lugar la tarde del 29 de diciembre en la catedral de Estocolmo. Después del oficio y en solemne procesión se trasladó el féretro al cementerio donde, por expreso deseo del fallecido, tuvo lugar la incineración.

Hasta pasado el funeral, los familiares de Nobel no sólo ignoraban el contenido del testamento sino incluso su existencia. En la tarde del 15 de diciembre, cuando todavía se encontraban en la Riviera, Emanuel y Hjalmar Nobel visitaron a Sohlman en el hotel para informarle que habían recibido un telegrama de Estocolmo comunicándoles que el testamento de su tío, depositado en el Enskilda Bank de dicha ciudad, había sido abierto y que el propio Ragnar Sohlman junto con Rudolf Lilljeqvist, un industrial sueco, habían sido nombrados albaceas. El telegrama no daba mas información sobre los términos del testamento excepto que por expreso deseo del testador después de su muerte debían abrírseles las venas y que solo una vez hecho esto y certificada su muerte por un médico cualificado, debía incinerarse su cuerpo.

Al día siguiente del funeral de San Remo llegó una carta de Estocolmo con el texto integro del testamento. Su contenido, que afectaba a todos los allí presentes de diferente forma, causó una primera impresión desalentadora, particularmente a Emanuel Nobel quien en un examen preliminar de los papeles que su tío había dejado en la casa de San Remo, encontró el viejo testamento datado el 14 de marzo de 1893, en el que el Alfred Nobel había hecho una anotación indicando que estaba cancelado y reemplazado por el nuevo del 27 de noviembre de 1895.

Emanuel Nobel comparó lógicamente los términos de los dos testamentos y comprobó como, en virtud de los cambios introducidos en el último quedaba, al igual que los restantes miembros de la familia, claramente marginado. Los defectos puramente formales del segundo testamento también se hacían evidentes cuando se comparaban con el primero. Por ejemplo, el principal heredero, la Fundación Nobel no existía y debía por tanto crearse y organizarse aunque resultaba confuso cuando y en qué términos debía hacerse y que ocurría mientras tanto con el futuro de compañías como la Bofors Company (en Suecia), la Nobel Dynamite Trust Company (en Inglaterra) o la Nobel Brothers Naphtha Company (en Rusia).

Tras arreglar algunos asuntos de Nobel en la villa de San Remo su sobrino Emanuel y Ragnar Sohlman viajaron a Suecia donde este último se reunió en Estocolmo con el otro albacea Mr. R. Lilljeqvist. Ambos eran bastante inexpertos en formalidades legales por lo que una de las prioridades fue encontrar un abogado sueco que guiase sus futuras acciones. Recurrieron a Carl Lindhagen, entonces Diputado de Justicia en la Cor- 
te de Apelación y la elección fue muy afortunada ya que Lindhagen tomo un gran interés no solo desde el punto de vista de las formalidades legales, sino que se implicó realmente en llevar adelante las ideas del testador. Se convirtió de hecho en un albacea mas.

El 2 de enero de 1897, cuatro días después del funeral, un periódico de Estocolmo publicaba casi íntegro el texto del testamento de Nobel, proclamando que una parte fundamental de su fortuna se dedicaría a una crear Fundación con el encargo de distribuir anualmente premios en cinco campos diferentes del esfuerzo y saber humano.

Esta noticia apareció antes de lo deseado por los albaceas, quienes esperaban encontrar entre los papeles de Nobel, en París o en San Remo, algunas directrices o instrucciones de cómo quería el testador que se llevaran a cabo realmente sus ideas. Estaba claro desde el principio que eran necesarias algunas aclaraciones adicionales y que el testamento era defectuoso desde el punto de vista formal. Como ya hemos apuntado el principal benefactor era una Fundación que todavía no existía y que por tanto había que crear, mientras que las instituciones designadas para elegir a los galardonados venían impuestas sin haber sido siquiera consultadas y sin recibir ninguna directriz para su actuación.

Además existían otros problemas de naturaleza puramente legal y no menos importantes: en primer lugar no estaba claro cuál era la residencia legal del testador y consecuentemente que tribunal tenía competencia para decidir sobre la validez del testamento y en segundo lugar era necesario hacer un inventario de los bienes y propiedades.

Desde diversos ámbitos comenzaron a surgir ataques, cada vez más virulentos, contra la idea fundamental del testamento, al tiempo que los defectos formales se esgrimían como razones de peso para declararlo nulo. También se inició una campaña de presión por parte de los allegados de Alfred Nobel que abogaban por llegar a un acuerdo para que el testamento se dividiese entre los familiares mas próximos y las instituciones suecas designadas para conceder los premios.

Algunos de los argumentos esgrimidos contra el testamento fueron: la falta de patriotismo mostrada por un sueco que, renegando de los intereses nacionales, quería apoyar ciertas actividades internacionales; la incapacidad de las instituciones designadas para conceder los premios para llevar a cabo satisfactoriamente su cometido, exponiendo a sus miembros al soborno y a la corrupción; y finalmente el hecho de que el Premio de la Paz debiera concederse por un comité nombrado por el Parlamento Noruego, lo cual entrañaba un gran peligro para los intereses suecos. 
Gradualmente, mas y mas periódicos, especialmente los conservadores, fueron incrementando las dudas sobre la posibilidad y conveniencia de aplicar el testamento. También desde la izquierda llegaron críticas que pasado el tiempo no dejan de resultar sorprendentes. Por ejemplo en un artículo a cuatro columnas, titulado: «El testamento de Alfred Nobel -magníficas intenciones- magnífico patinazo» el líder social demócrata Hjalmar Branting criticaba al testador desde el punto de vista teórico y práctico.

Los albaceas se veían obligados a hacer frente a las formalidades legales, llevar a cabo las transacciones económicas relacionadas con la liquidación de las propiedades y la reinversión de todo el capital en «seguridades de primera clase» como especificaba el testamento y a la organización de un cuerpo administrativo adecuado para el manejo de los fondos y la formulación de las normas para la distribución anual de los premios.

Uno de los puntos más conflictivos fue sin duda el problema de la jurisdicción. Desde que a los nueve años Nobel abandonó Suecia con su madre y sus hermanos para ir a Rusia nunca tuvo residencia legal en ningún país. Cuestión prioritaria pues era fijar cual había sido su residencia legal. Ragnar Sohlman viajo a París para poner orden en algunos de los papeles de Nobel y comprobó que traería muchos problemas declararle francés. Desde todos los puntos de vista parecía extremadamente urgente establecer que la residencia legal de Nobel, y consecuentemente la jurisdicción sobre la que basarse, estaba en Suecia. Tratar de argumentar ante las autoridades francesas que su último domicilio había estado en Estocolmo, donde había vivido hasta los nueve años, habría ido en contra de las leyes francesas. La única esperanza de que se reconociera un domicilio «de facto» sueco era reclamar que la casa de Björkborn, cerca de Bofors, había sido su residencia legal durante los años que precedieron a su muerte y que la Corte local de Karlskoga tenía, consecuentemente, jurisdicción sobre todos los asuntos que afectaban tanto al testamento como a sus bienes.

\section{La negociación con los herederos y las Instituciones que debían conceder los premios}

Tras reunirse en Estocolmo con Lindhagen los albaceas decidieron enviar una serie de cartas a las diferentes instituciones suecas señaladas en el testamento por Nobel para seleccionar los ganadores de los premios, pidiéndoles que asumieran su responsabilidad. Por ejemplo el texto de la carta que se envió a la Academia de Ciencias fue el siguiente: 
Caballeros,

Los abajo firmantes designado por el fallecido Dr. Alfred Nobel como albaceas de su última voluntad tenemos el honor de hacerles llegar una copia certificada de su testamento con la respetuosa petición de que la Academia acepte el nombramiento para conceder los premios en Física y Quimica así como de informarnos de su decisión.

Sin embargo, es obvio que con relación a las condiciones y procedimientos relativos a la concesión de los premios establecidos por el Dr. Nobel se requiere una regulación mas detallada que los términos generales contenidos en su testamento. Por lo que respecta a los premios que deben presentarse en Suecia, nos parece que lo mas procedente sería tener una reunión con personas representativas de las instituciones adjudicatarias de los premios: por ejemplo dos representantes de la Academia de Ciencias y uno del Instituto Carolino y la Academia Sueca, respectivamente quienes junto con nosotros deberían tratar el tema.

Subsiguientemente, una propuesta definitiva aprobada por las mencionadas instituciones y por los abajo firmantes debería ser enviada a Su Majestad el Rey a través del Ministro de Educación y Asuntos Eclesiásticos con la humilde petición de que Su Majestad lo sancione. También es nuestra intención enviar al mismo tiempo a Su Majestad nuestras sugerencias sobre las reglas necesarias en relación con el manejo de los fondos de la Fundación.

Por todo lo anterior y asumiendo que la Academia acepta la responsabilidad en cuestión, pedimos que designen dos delegados, quienes junto con el del Instituto Carolino y el de la Academia Sueca tratarán con nosotros sobre los detalles de las regulaciones de los términos y métodos de concesión de los premios.

\section{Firmado: Ragnar Sohlman Rudolf Lilljequist}

Ragnar Sohlman viajó de nuevo a Francia para comenzar a transferir, con la máxima discreción posible, los bienes de Nobel depositados en el banco Rothschild de París. Inicialmente se pensó en que Sohlman hiciese personalmente algunos viajes a Londres y posteriormente a Estocolmo transportando el dinero y los objetos de valor, pero como la idea parecía demasiado arriesgada y también algo lenta, se decidió recurrir a los envíos postales aunque las oficinas de correos francesas no aseguraban ningún paquete con mas de 20.000 francos. El Rothschild tenía estipulado, además, que el valor de los envíos diarios no debían exceder los dos millones y medio de francos.

A lo largo de una semana se fue sacando el dinero de las cámaras acorazadas de la Comptoir National d’Escompte para trasladarlo a las de- 
pendencias del Consulado General Sueco de la calle Pépinière, donde era empaquetado y sellado. Por la tarde se trasladaba a la Expédition des Finances para ser enviado a Londres o Estocolmo, según los casos. Se tomaron las debidas precauciones para no llamar excesivamente la atención y todos los traslados los hacía Ragnar Sohlman personalmente quien provisto de un revolver transportaba discretamente una maleta con el dinero.

Retrospectivamente, parece mas lógico preguntarse por qué no se recurrió simplemente a una transferencia bancaria habitual. El temor era que dicha orden podría haber llamado la atención de las autoridades francesas, máxime en unos momentos en que todavía estaba pendiente el tema de si había que pagar impuestos a Francia por el problema de la residencia legal de Nobel.

Uno de los días que se llevaban a cabo estos traslados, el Cónsul Sueco, recibió en su oficina de París la visita de Hjalmar y Ludvig Nobel, que habían viajado para discutir el problema de la residencia legal de su tío Alfred y la validez del testamento. Mientras tenía lugar esta reunión Seligmann y Sohlman estaban ocupados en la habitación contigua anotando y empaquetando el dinero de Nobel, pero los ilustres visitantes no se percataron de su presencia. Como representante oficial de Suecia, el Cónsul se sentía en una posición incómoda y tras el episodio que acabamos de comentar propuso que se debería informar a los familiares de lo que realmente estaba ocurriendo allí, para lo cual sugirió celebrar una cena de «reconciliación» al día siguiente.

La cena tuvo lugar en el restaurante Noël Peter en el Passage des Princes y a los postres empezaron a tratar el tema de la residencia legal de Alfred Nobel y la validez de su testamento. Hjalmar Nobel argumentó que el intento de fijar la residencia en Bofors era una pretensión inaceptable y que debía admitirse que el domicilio legal de su tío era París donde había vivido durante 17 años y donde todavía era posible encontrar su casa y sus criados. Los sobrinos de Nobel planteaban por tanto que el tribunal apropiado para decidir sobre los derechos legales debía ser la Corte francesa y que ésta tendría que pronunciarse también sobre la validez del testamento. Una decisión de las cortes francesas señalando que el domicilio de Alfred Nobel había estado en París no solo habría obligado a pagar impuestos en Francia, sino que habría declarado nulo el testamento por sus defectos formales, perfectamente tipificados en las leyes francesas.

Ragnar Sohlman replicó que indudablemente el tema estaba abierto a debate pero que realmente esta discusión ya sólo tenía un interés meramente teórico puesto que el dinero y las pertenencias importantes de Alfred Nobel ya no se encontraban en París y que por tanto difícilmente 


\section{Premios Nobel}

podrían caer bajo jurisdicción francesa. Estas palabras causaron sensación y Hjalmar, atónito, se negó a creerlas en un principio, pero el Cónsul las confirmó.

El resultado inmediato del anuncio de Ragnar Sohlman fue un aumento de las actividades hostiles de Hjalmar Nobel y del resto de los familiares que representaba. Se rumoreó que se puso en contacto con los abogados mas prominentes de Francia que se sorprendieron de la situación y le dijeron, al parecer, que había estado ciego por no haber inmovilizado antes los bienes de su tío. Siguiendo su consejo Hjalmar Nobel reclamó y bloqueó las propiedades que todavía quedaban en París, decisión que afectó a la casa de la Avenue Malakoff, cuya venta quedó por tanto impedida. Hjalmar Nobel se trasladó igualmente a Alemania donde por medio de sus abogados intentó bloquear las propiedades de Nobel allí pero Ragnar Sohlman ya se había anticipado y contactado con el Dr. Scharlach un eminente jurista que aconsejado por los directores de la German Dynamite Company protegió los intereses de los albaceas así como la integridad de los mas de seis millones de coronas que estaban depositadas en los bancos alemanes.

En Suecia, las primeras escaramuzas se produjeron durante la primavera de 1897. Formalmente habían comenzado con la discusión entre Estocolomo y Bofors, para determinar que corte tenía jurisdicción sobre los bienes de Nobel. La decisión fue finalmente favorable a la Corte de Karlskoga bajo cuya jurisdicción estaba Bofors.

En la mayoría de los círculos de poder de las instituciones designadas como jurados de los premios también aparecieron diferencias de opinión sobre la conveniencia de asumir las nuevas responsabilidades y se expresaron dudas sobre si la posible aceptación podría perjudicar a los miembros de los jurados e incluso a la investigación científica en Suecia. El debate sobre este punto fue especialmente vivo en la Academia Sueca y en la Real Academia de Ciencias. También algunos miembros del Instituto Carolino, liderados por el Profesor Axel Key, se manifestaron a favor de un cambio sustancial de las bases del testamento de forma que las instituciones nominadas pudiera tener mayor libertad para utiliza la cuota de la herencia Nobel a su mejor conveniencia.

A su regreso a Estocolmo desde Francia, en Mayo de 1897, Ragnar Sohlman reunió, por sugerencia de Lindhagen, a algunos de los miembros mas influyentes de las instituciones implicadas. Además de Carl David, entonces Secretario Permanente de la Academia Sueca, convocó a su Presidente, Hans Forssell, un destacado historiador, publicista y político así como miembro de la Academia de Ciencias, al Profesor Magnus Gustaf Retzius del Instituto Carolino y al Profesor Adam Smitt, Profesor 


\section{Juan Fernández Santarén}

de Zoología de la Universidad de Estocolmo, ambos miembros de la Academia de Ciencias y finalmente al Profesor Axel Key, Rector del Instituto Carolino.

En dicha reunión Forssell dijo que el se oponía personalmente a que las Academias de las cuales era miembro aceptasen las nuevas obligaciones pero que creía que en ambas instituciones nadie compartía esta opinión. Sin embargo, añadió que se comprometía a intentar que las Academias asumieran la responsabilidad.

Los otros asistentes mostraron una actitud mas favorable. El Profesor Key tenía incluso preparado un borrador para la aceptación por parte del Instituto Carolino de las nuevas obligaciones que incluía la conformidad del Instituto para designar un delegado que le representase en futuras reuniones. Posteriormente el Instituto nombro al propio Profesor Key para llevar a cabo esta misión, siendo sustituido tras su jubilación por Count K. A: H. Mörner, también Profesor del Instituto.

Por su parte la Academia de Ciencias nombró un comité especial para estudiar la cuestión. El 7 de Mayo de 1897 dicho comité recomendó aceptar la responsabilidad pero sugiriendo que se clarificasen, con la mayor precisión posible, todos los aspectos legales pendientes para evitar problemas en la aplicación práctica del testamento. Sin embargo Hans Forssell, que ya había sido derrotado en la Academia Sueca, tuvo éxito al conseguir el rechazo de las recomendaciones de este comité y convencer a la Academia de Ciencias para no aceptar su condición de jurado de los premios hasta que el testamento no estuviese aprobado legalmente.

Dada la actitud negativa de la Academia de Ciencias, que ya había sido designada como otorgadora de los premios de Física y Química, el problema de la aprobación del testamento entró en un punto muerto, una situación que ya había sido anticipada por Forssell, quien había expresado desde el principio su deseo de frustrar el proyecto en su conjunto.

Para aprobar el testamento era absolutamente necesario que las instituciones concesionarias de los premios aceptasen por anticipado sus respectivas asignaciones ya que de otra forma el testamento era nulo. Y cuando una de estas instituciones rechazaba incluso el elegir delegados para discutir los términos en los que debería aceptar dicha responsabilidad no era posible siquiera iniciar las negociaciones. No se podía por tanto progresar en este punto.

La situación forzaba a los albaceas a tratar de alcanzar algún tipo de compromiso con los familiares que estaban representados por un prominente abogado de Gothenburg, el Dr. Philip Leman, quien ya había manifestado su intención de llegar a un acuerdo amistoso. 
Con objeto de aclarar el panorama se decidió invitar a una serie de asesores legales extranjeros a una reunión con Lindhagen y con los albaceas a primeros de Julio de 1897 en Estocolmo. El 2 y 3 de Julio se reunieron en el Hotel Rydberg de dicha ciudad con Maitre Coulet de París, Mr. Timothy Warren de Glasgow, y el Dr. Wesphal de Hamburgo. Las conclusiones de la reunión fueron que Coulet y Warren consideraban favorables las respectivas situaciones en Francia y Gran Bretaña al punto de opinar que no había ningún peligro de posteriores acciones legales contra la validez del testamento en esos países, mientras que Wesphal recomendaba llegar a un acuerdo con los familiares.

Por otra parte, el tamaño de la fortuna de Alfred Nobel y su amplia distribución por diferentes países habían demorado el trabajo de los albaceas sobre la elaboración de un inventario de bienes hasta el punto de tener que solicitar permiso en dos ocasiones a la Corte de Karlskoga para retrasar el informe. No obstante el trabajo progresó y finalmente se celebró un acto oficial el 30 de Octubre de 1897 en Bofors en el que se dio cuenta de los bienes de Nobel y al que fueron invitados sus herederos. Solo Hjalmar Nobel hizo acto de presencia. Antes de empezar, el representante de los herederos suecos entregó una protesta escrita contra la legalidad del procedimiento basada en una serie de puntos que afortunadamente no tuvieron efecto.

El inventario se completó y se envió finalmente a la Corte de Karlskoga el 9 de Noviembre de 1897, es decir aproximadamente once meses después de la muerte de Nobel.

En dicho inventario, y por consejo de Lindhagen, se habían hecho dos apartados:

A. Fondos libres de impuestos . . . . . . 18,123,043.42 Kr

B. Fondos sometidos a impuestos . . . . . 15,110,748.78 Kr Total . . . . . $33,233,792.20 \mathrm{Kr}$

El pasivo se estimó en . . . . . . . . . 1,646,589.92 Kr

Neto . . . . . . . 31,587,202.28 Kr

La distribución geográfica de los bienes de Nobel en el momento de su fallecimiento de acuerdo con los países en los que estaban depositados era la siguiente:
Suecia .............
$5,796,140.00 \mathrm{Kr}$
Noruega . . . . . . . . . . .
Alemania ...........
Austria ........... $94,472.28 \mathrm{Kr}$
$6,152,250.95 \mathrm{Kr}$ $228,754.20 \mathrm{Kr}$ 


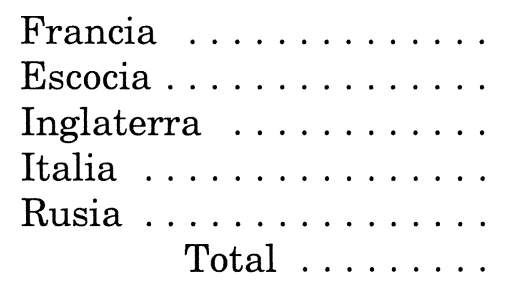

$$
\begin{array}{r}
7,280,817.23 \mathrm{Kr} \\
3,913,938.67 \mathrm{Kr} \\
3,904,235.32 \mathrm{Kr} \\
630,410.10 \mathrm{Kr} \\
5,232,773.45 \mathrm{Kr} \\
33,233,792.20 \mathrm{Kr}
\end{array}
$$

En Navidad de 1897 se intentó buscar una salida al punto muerto que había provocado el rechazo de la Academia de Ciencias a nombrar delegados. Se decidió reunir a los representantes de la Academia Sueca y del Instituto Carolino, Dr. Wirsén y Count Mörner respectivamente, para hablar de manera informal con los albaceas y con su abogado sobre la aplicación del testamento sin esperar a la Academia de Ciencias. A lo largo de seis reuniones, de las que se conservan las actas, durante los meses de Enero y Febrero de 1898 se discutió sobre las bases de la futura Fundación Nobel. De forma voluntaria, y sin representar oficialmente a la Academia de Ciencias, también asistieron los Profesores L. F. Nilson y Otto Pettersson. En estas reuniones se alcanzó un acuerdo sobre los principios generales que deberían seguirse para elaborar los futuros estatutos.

A las dos últimas reuniones también se invitó a Emanuel Nobel en representación de los familiares que vivían en Rusia. En dicha condición, y en la reunión del 11 de febrero de 1898, hizo una aportación que resultó decisiva para la aceptación del testamento y por tanto para el futuro de la Fundación Nobel. A este respecto, el segundo párrafo del acta de aquel día dice lo siguiente:

«El Sr. Nobel expresó que desea respetar la última voluntad de su tío tal como éste la dejo reflejada en el testamento. Consecuentemente, el no intenta discutir sus términos. Sin embargo, para alcanzar los deseos de su tío será necesario hacer ciertas alteraciones y adiciones al testamento que no podrán llevarse a cabo sin el consentimiento de todos los herederos. El Sr. Nobel pide por tanto que se le informe de todos los cambios que se propongan con objeto de decidir, después de contrastarlos con los deseos y planes de su tío, si el y sus parientes mas próximos los aprueban».

La actitud de Emanuel Nobel hay que valorarla en su justa medida. Personalmente se encontraba en una posición muy difícil ya que si bien tenía desde el principio la idea de no interferir con las disposiciones de su tío estaba sometido, como portavoz de la rama de la familia que vivía en Rusia, a fuertes presiones para intentar que cambiase su actitud y se opusiese también al testamento. Señalemos que solo diez días antes los 


\section{Premios Nobel}

parientes que vivían en Suecia habían emprendido acciones legales contra el testamento. Iban dirigidas contra los albaceas del testamento, el Gobierno Sueco, el Parlamento Noruego y las tres instituciones suecas designadas como jurados de los premios. Los demandantes representaban a doce de los veinte descendientes que se beneficiarían si el testamento era declarado nulo.

Las presiones sobre Emanuel Nobel no sólo llegaron de sus familiares sino también de las mas altas esferas del poder. Uno de los primeros días de febrero de 1898 recibió una comunicación del Rey Oscar quien quería discutir el tema con el. En la entrevista el monarca trató de persuadirle para cambiara algunos términos del testamento llegando incluso a decirle: «lo que debe hacer usted es olvidarse de las ideas fantásticas de su tío y velar por los intereses de su familia». La respuesta de Emanuel Nobel fue tajante: "Majestad yo no quiero correr el riesgo de que en un futuro se pueda llegar a acusar a mis hermanos de que se han apropiado de unos fondos que realmente pertenecen a los científicos». La conversación concluyó en este punto. Cuando Emanuel contó lo ocurrido en la audiencia a su abogado ruso, este le recomendó que abandonase inmediatamente Estocolmo y regresase a St. Petersburg para evitar ser arrestado bajo acusación de lesa majestad.

Emanuel reunió a la familia para explicarles la situación a la que se había llegado y pedirles su aprobación a la actitud que intentaba seguir en el tema del testamento con objeto de proteger el honor de la familia Nobel, así como los intereses económicos de los familiares, que se centraban básicamente en adquirir el control de las rentas de la Nobel Brothers Company en Baku, que su tío había dirigido.

La decisión de Emanuel Nobel dio sus frutos y finalmente el 5 de junio de 1898 los familiares firmaron en Estocolomo un documento ante notario público declarando que reconocían la validez del testamento de $\mathrm{Al}$ fred Nobel y rechazaban emprender futuras reclamaciones. A cambio recibían una serie contraprestaciones que salvaguardaban, de forma adecuada, los intereses de la familia.

Consecuentemente tras estos acontecimientos, se retomó la discusión sobre la distribución de los premios. Los primeros pasos en esta dirección fueron enviar cartas idénticas a las distintas instituciones, fechadas el 27 de marzo de 1898 en las que se las informaba del actual estado de la situación. En la carta a la Academia de Ciencias, que había rechazado el nombrar ningún delegado hasta que el testamento tuviese validez legal, pero que había estado representada informalmente en las reuniones por dos de sus miembros, se hacía hincapié en que dado que Emanuel Nobel había decidido apoyar de manera explícita el testamento de su tío ya no 


\section{Juan Fernández Santarén}

había duda de que este tendría efecto. En vista de este cambio de situación, se le pedía una vez mas a la Academia que designase delegados oficiales para tomar parte en las discusiones encaminadas a elaborar los futuros estatutos de la Fundación Nobel.

Aproximadamente seis semanas mas tarde, el 11 de Mayo de 1898, la Academia contestó que nombraba al Profesor L. F. Nilson y a B. Hasselberg como representantes oficiales para todas las cuestiones relativas al testamento y a las futuras normas para la distribución de los premios. El camino parecía despejarse y así fue.

En el acuerdo con los familiares Nobel también se incluyeron ciertos apartados que posteriormente se incorporaron a los estatutos de la Fundación Nobel. Esas disposiciones fueron las siguientes:

a) Los estatutos generales que afecten a la forma y condiciones para la concesión de los premios, se hará, tal como queda dicho en el testamento, mediante consulta con un representante de la familia de Robert Nobel siendo posteriormente enviado para su aprobación a la Corona.

b) No habrá modificaciones en de los siguientes principios fundamentales: cada uno de los futuros premios establecidos por el testamento se concederá al menos una vez por cada periodo de cinco años, a partir del año inmediatamente después al que la Fundación Nobel comience sus actividades, y la dotación de un premio nunca será inferior al sesenta por ciento de los intereses anuales generados por los fondos asignados para cada premio, ni podrá dividirse en mas de tres partes a la vez. (Estatutos de la Fundación Nobel, Art. I).

Alcanzado el acuerdo debía ser aprobado por el Gobierno Sueco y por todas las instituciones adjudicatarias de los premios. Dicha aprobación fue sancionada por el Instituto Carolino el 7 de Junio, por la Academia Sueca el 9 de Junio y por la Real Academia de Ciencias el 11 de Junio de 1898. A través de Lindhagen los representantes de todas esas instituciones habían estado puntual y permanentemente informados sobre el progreso de las negociaciones, lo que explica la rapidez en la aprobación de las propuestas formales.

Respecto de la parte Noruega, la situación fue un poco diferente y hubo que informar a sus delegados sobre lo que se había hecho y discutido en relación con el testamento. Después de haber aceptado, el 26 de Abril de 1897, ser los designadores de los premios de la Paz, el Parlamento nombro el 7 de Agosto de ese mismo año un comité integrado por los tres ministros, Schweigaard, Steen y Blehr para redactar un primer documento. Una vez realizado este trabajo el 19 de Junio de 1898 se de- 
signo un nuevo comité integrado por el presidente del Parlamento, V. Ullman y dos de sus miembros, Jacob Lindboe y Emil Stang para estudiarlo y llegado el caso, aprobarlo. Los albaceas testamentarios, su abogado Carl Lindhagen y Judge Santesson que ya había representado al Parlamento en las cuestiones relativas al testamento Nobel en Suecia viajaron a Oslo a primeros de Julio de 1898 para discutir la situación con el comité noruego. Tras un par de reuniones el 4 de Julio de 1898 se aceptaron los términos del acuerdo y el 9 de Septiembre de ese mismo año el gobierno sueco dio su aprobación formal una vez que tuvo en su poder todos los documentos.

\section{La Fundación Nobel}

Tras la homologación del testamento de Alfred Nobel se convocó una nueva reunión con los delgados de las instituciones que otorgaban los premios para el 19 de Noviembre de 1898 en la que la Real Academia de Ciencias ya estuvo oficialmente representada por los dos profesores mencionados anteriormente.

De acuerdo con los estatutos propuestos, cada uno de los Comités Suecos debían formular sus propias directrices para que posteriormente fuesen aprobadas por el gobierno sueco. Las normas sobre el premio de la paz las debía confeccionar el Parlamento Noruego.

En esa reunión surgieron algunos problemas sobre la organización de los Institutos Nobel y la forma de seleccionar los ganadores y también se añadió que «en orden a su validez, ninguno de los estatutos especiales puede contener ninguna cláusula que entre en conflicto con los estatutos básicos». En este punto los noruegos objetaron que eso sería tanto como colocar al Comité Nobel Noruego bajo la jurisdicción de las autoridades suecas. Se decidió entonces no hacer mención de los estatutos particulares en el documento principal, y se permitió que el Comité Noruego crease sus propias normas. Nunca ha habido ningún conflicto en esta materia.

El texto definitivo de los «Estatutos de la Fundación Nobel» se aprobó finalmente el 27 y 28 de Abril y fue enviado por los albaceas al gobierno sueco para su examen y sanción formal. Contenía algunas aclaraciones y adiciones al testamento así como ciertas directrices de naturaleza financiera o administrativa.

Las aclaraciones cubrían los siguientes puntos:

a) Se utilizó «La Academia en Estocolmo» como forma de referirse a la Academia Sueca. 
b) El término «literatura» no solo abarcaba el trabajo literario propiamente dicho sino otros trabajos que en virtud de su contenido y estilo tuvieran valor literario.

c) La implicación de que los premios debían de concederse a trabajos «producidos durante el año precedente» debía interpretarse en el sentido de que para la concesión del premio debían tenerse en cuenta únicamente los últimos trabajos, mientras que los trabajos anteriores debían considerarse solo si su importancia se había establecido recientemente.

d) Para que un trabajo escrito pudiera optar a premio debía haber sido impreso.

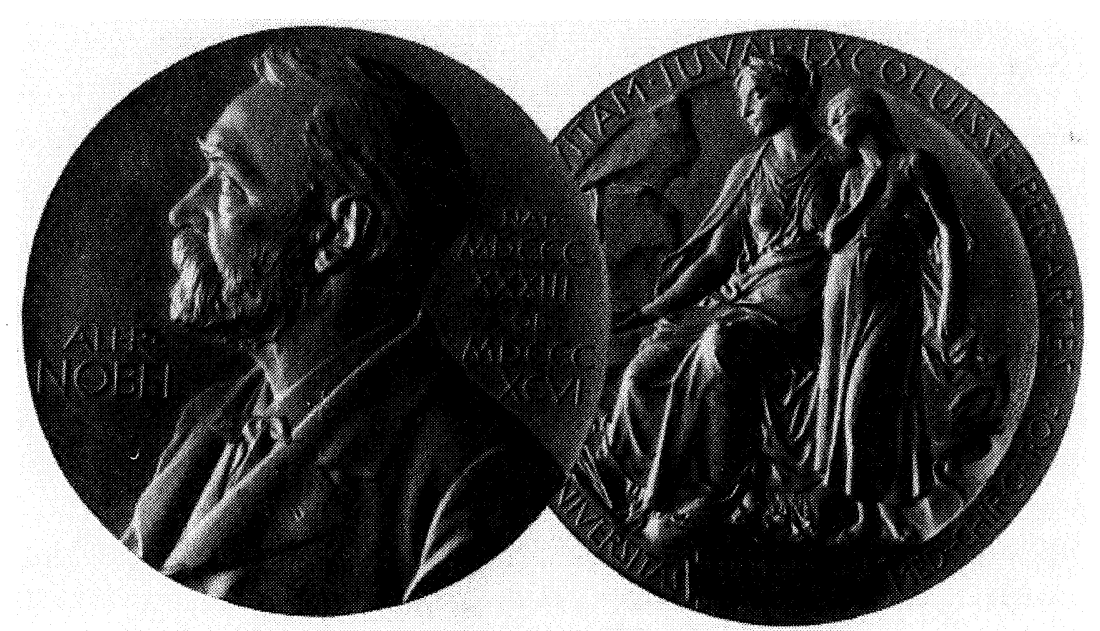

Anverso y reverso de la Medalla Nobel que se otorga a los galardonados con el Premio Nobel de Fisiología y Medicina. La reproducida corresponde concretamente a la recibida por Santiago Ramón y Cajal en 1906.

Las adiciones al testamento afectaban a los siguientes puntos fundamentales:

a) Un premio puede dividirse entre dos galardonados, si cada uno de ellos se considera que es merecedor del premio. También puede premiarse a dos o más personas que hayan llevado a cabo un trabajo de manera conjunta.

b) El dinero asignado a un premio que haya quedado vacante debe retornar a los fondos de procedencia o colocarse en unos fondos especiales que se utilizaran de acuerdo con la última voluntad del testador.

c) Para ayudar en las deliberaciones preliminares de los trabajos propuestos para la concesión del premio, las instituciones suecas 


\section{Premios Nobel}

adjudicatarias deben nombrar un Comité Nobel integrado por entre tres y cinco miembros, mientras que para la concesión del Premio de la Paz se nombrará un Comité Nobel especial designado por el Parlamento Noruego.

d) Para facilitar el trabajo relacionado con la selección de ganadores de los premios, los adjudicatarios de los mismos pueden organizar instituciones científicas que deben pertenecer a la Fundación Nobel y se denominarán «Institutos Nobel».

Desde el punto de vista financiero, se decidió que del presupuesto anual de los fondos generales destinados para cada premio, se podía destinar una cuarta parte cubrir los gastos derivados de la selección de los ganadores y los que generase su correspondiente Instituto Nobel.

Posteriormente se estipuló que la Fundación debería regirse por un Comité de cinco miembros, con suplentes, que debían encargarse del manejo de las finanzas y de su administración general. El Director de este Comité y su suplente debía ser designado por el gobierno sueco y los otros cuatro miembros, con dos suplentes, debían ser seleccionados de entre personas de total confianza por las instituciones concesionarias de los premios. Después de la auditoria anual, los electores debían tener el derecho de relevar a los miembros de sus responsabilidades financieras.

Finalmente, en los estatutos provisionales se señalo la necesidad de destinar una partida presupuestaria para la adquisición de todo lo necesario para empezar a funcionar administrativamente, así como una suma de 300,000 coronas para cada uno de los jurados de los premios, que daban una suma total de 1,500.000 coronas como fondos para la organización de los respectivos Institutos Nobel.

Tras introducir pequeños detalles de naturaleza formal, el Gobierno aprobó los estatutos propuestos por el comité el 29 de junio de 1900 y ese mismo día fueron oficialmente promulgados como decreto por su Majestad el Rey Oscar II.

El 25 de septiembre de 1900 los administradores de la Fundación Nobel se reunieron por primera vez convocados por el miembro de mayor edad electo por la Academia de Ciencias, R. Törnebladh, director del banco de Suecia. La lista completa de aquellos primeros administradores fue la siguiente:

Por la Academia Sueca: Hans Forsell, su Presidente, Carl David af Wirsén, su Secretario permanente, y P. J. von Ehrenheim primer Ministro del Gabinete.

Por la Real Academia Sueca de Ciencias: A, R. Akerman, Presidente de la «Board of Trade», A. E. Törnebohm, Director del «Geological Survey», R. Törnebladh, Director del Banco de Suecia, E. Sidenbladh, Director del 


\section{Juan Fernández Santarén}

«Statistical Office», Chr. Aurivillius, Conservador del Museo de Historia Natural, y J. E. Cederblom. Profesor en el Real Instituto de Tecnología.

Por el Instituto Carolino Médico-Quirúrgico: Count K. A. H. Mörner, su Rector, Jonas Waern, Profesor de Medicina y Ernst Almquist, Profesor de Medicina.

Por el Comité Nobel del Parlamento Noruego: Su excelencia, O. A. Blehr, Primer Ministro de Noruega, B. Getz, Presidente del Consejo del Poder Judicial General de Noruega y C. Berner, Presidente del Parlamento.

P. J. von Ehrenheim fue elegido Chairman de los administradores, después de lo cual la reunión se prolongó durante dos días para considerar en privado la selección del Comité. Las siguientes personas fueron elegidas como primeros miembros del Comité de la Fundación Nobel: Hans Forssell, R. Törnebladh, Henrik Santesson y Ragnar Sohlman.

Como primer Presidente el Gobierno nombró por unanimidad al Primer Ministro E. G. Boström. El Comité se reunió por primera vez el 3 de Octubre de 1900 y se nombro Director Ejecutivo a Henrik Santesson.

La larga batalla sobre el testamento de Alfred Nobel y la realización de sus deseos había llegado a su fin. Al año siguiente, 1901, se concedieron los Premios Nobel por primera vez. El tiempo, ahora cien años, ha sido el encargado de ir prestigiando a su fundador, a la Fundación Nobel y a los galardonados.

\section{Bibliografía}

http://www.nobel.se

http://www.aldeaeducativa.com/aldea/Nobel.asp

J. ERIK JoRPES. «Alfred Nobel». Journal of Chemical Education. Vol. 37, (1960), 328-334.

Sten Söderberg. "Alfred Nobel. A lonely man». The Nobel Prize 1963 International annual English edition. pg 43-49.

J. H. Schück, R. Sohlman, A. Osterling, G. Liljestrand, A. Westgren, M. Siegbahn, A. SCHON and N. K. StAHLE. "Alfred Nobel: The man and his prizes». 1950. The Nobel Foundation, Stockholm. 


\section{Relación de Galardonados con el Premio Nobel (1901-2000)}

\begin{tabular}{|c|c|}
\hline AÑO & Física \\
\hline 1901 & W. C. Röntgen (Alemania) \\
\hline \multirow[t]{2}{*}{1902} & H. A. Lorentz (Holanda) \\
\hline & $\begin{array}{l}\text { P. Zeeman (Holanda) } \\
\text { H. A. Becquerel (Francia) }\end{array}$ \\
\hline \multirow{2}{*}{1903} & P. Curie (Francia) \\
\hline & Marie S. Curie (Francia) \\
\hline 1904 & Lord Rayleigh (Gran Bretaña) \\
\hline 1905 & P. E. A. von Lenard (Alemania) \\
\hline 1906 & J. J. Thomson (Gran Bretaña) \\
\hline 1907 & A. A. Michelson (U. S. A.) \\
\hline 1908 & G. Lippmann (Francia) \\
\hline \multirow[t]{2}{*}{1909} & G. Marconi (Italia) \\
\hline & C. F. Braun (Alemania) \\
\hline 1910 & J. D. van der Waals (Holanda) \\
\hline 1911 & W. Wien (Alemania) \\
\hline 1912 & N. G. Dalén (Suecia) \\
\hline 1913 & H. Kamerlingh Onnes (Holanda) \\
\hline 1914 & M. von Laue (Alemania) \\
\hline \multirow[t]{2}{*}{1915} & W. H. Bragg (Gran Bretaña) \\
\hline & W. L. Bragg (Gran Bretaña) \\
\hline 1916 & No hubo premio \\
\hline 1917 & C. G. Barkla (Gran Bretaña) \\
\hline 1918 & M. K. E. L. Planck (Alemania) \\
\hline 1919 & J. Stark (Alemania) \\
\hline 1920 & C. E. Guillaume (Suiza) \\
\hline
\end{tabular}

Química

J. H. van't Hoff (Holanda)

H. E. Fischer (Alemania)

S. A. Arrhenius (Suecia)

W. Ramsay (Gran Bretaña)

A. von Baeyer (Alemania)

H. Moissan (Francia)

E. Buchner (Alemania)

E. Rutherford (Gran Bretaña)

W. Ostwald (Alemania)

O. Wallach (Alemania)

Marie Curie (Francia)

V. Grignard (Francia)

P. Sabatier (Francia)

A. Werner (Suiza)

T. W. Richards (U. S. A.)

R. M. Willstätter (Alemania)

No hubo premio

No hubo premio

F. Haber (Alemania)

No hubo premio

W. H. Nernst (Alemania)
Fisiología y Medicina

E. A. von Behring (Alemania)

R. Ross (Gran Bretaña)

N. R. Finsen (Dinamarca)

I. P. Paulov (Rusia)

R. Koch (Alemania)

C. Golgi (Italia)

S. Ramón y Cajal (España)

C. L. A. Laveran (Francia)

P. Ehrlich (Alemania)

I. I. Metchnikov (Rusia)

E. T. Kocher (Suiza)

A. Kossel (Alemania)

A. Gullstrand (Suecia)

A. Carrel (U. S. A.)

C. R. Richet (Francia)

R. Bárány (Austria)

No hubo premio

No hubo premio

No hubo premio

No hubo premio

J. Bordet (Bélgica)

S. A. S. Krogh (Dinamarca) 
F. Sody (Gran Bretaña)

F. W. Aston (Gran Bretaña)

F. Pregl (Austria)

No hubo premio

R. A. Zsigmondy (Alemania)

T. Svedberg (Suecia)

H. O. Wieland (Alemania)

A. O. R. Windaus (Alemania)

A. Harden (Gran Bretaña)

H. K. A. S. von Euler (Suecia)

H. Fischer (Alemania)

C. Bosch (Alemania)

F. Bergius (Alemania)

I. Langmuir (U. S. A.)

No hubo premio

H. C. Urey (U. S. A.)

F. Joliot (Francia)

Irène Joliot-Curie (Francia)

P. J. W. Debye (Holanda)

W. N. Haworth (Gran Bretaña)

P. Karrer (Suiza)
No hubo premio

A. V. Hill (Gran Bretaña)

O. F. Meyerhof (Alemania)

F. G. Banting (Canada)

J. J. R. Macleod (Canada)

W. Einthoven (Holanda)

No hubo premio

J. A. G. Fibiger (Dinamarca)

J. Wagner-Jauregg (Austria)

C. J. H. Nicolle (Francia)

C. Eijkman (Holanda)

F. G. Hopkins (Gran Bretaña)

K. Landsteiner (Austria)

O. H. Warburg (Alemania)

C. S. Sherrington (Gran Bretaña)

E. D. Adrian (Gran Bretaña)

T. H. Morgan (U. S. A.)

G. H. Whipple (U. S. A.)

G. R. Minot (U. S. A.)

W. P. Murphy (U. S. A.)

H. Spemann (Alemania)

H. H. Dale (Gran Bretaña)

O. Loewi (Austria)

A. von Szent-Györgyi (Hungría) 


\begin{tabular}{|c|c|}
\hline AÑO & Física \\
\hline 1938 & E. Fermi (Italia) \\
\hline 1939 & E. O. Lawrence (U. S. A.) \\
\hline 1940 & No hubo premio \\
\hline 1941 & No hubo premio \\
\hline 1942 & No hubo premio \\
\hline 1943 & O. Stern (U. S. A.) \\
\hline 1944 & I. I. Rabi (U. S. A.) \\
\hline 1945 & W. Pauli (Austria) \\
\hline 1946 & P. W. Bridgman (U. S. A.) \\
\hline 1947 & E. V. Appleton (Gran Bretaña) \\
\hline 1948 & P. M. S. Blackett (Gran Bretaña) \\
\hline 1949 & H. Yukawa (Japón) \\
\hline 1950 & C. F. Powell (Gran Bretaña) \\
\hline 1951 & $\begin{array}{l}\text { J. D. Cockcroft (Gran Bretaña) } \\
\text { E. T. S. Walton (Irlanda) }\end{array}$ \\
\hline 1952 & $\begin{array}{l}\text { F. Bloch (U. S. A.) } \\
\text { E. M. Purcell (U. S. A.) }\end{array}$ \\
\hline 1953 & F. Zernike (Holanda) \\
\hline
\end{tabular}

Química

R. Kuhn (Alemania)

A. F. J. Butenandt (Alemania)

L. Ruzicka (Suiza)

No hubo premio

No hubo premio

No hubo premio

G. de Hevesy (Hungría)

O. Hahn (Alemania)

A. I. Virtanen (Finlandia)

J. B. Sumner (U. S. A.)

W. M. Stanley (U. S. A.)

J. H. Northrop (U. S. A.)

R. Robinson (Gran Bretaña)

A. W. K. Tiselius (Suecia)

W. F. Giauque (U. S. A.)

O. P. H. Diels (Alemania)

K. Alder (Alemania)

\section{E. M. McMillan (U. S. A.)}

G. T. Seaborg (U. S. A.)

A. J. P. Martin (Gran Bretaña)

R. L. M. Synge (Gran Bretaña)

H. Staudinger (Alemania)
Fisiología y Medicina

C. J. F. Heymans (Bélgica)

G. Domagk (Alemania)

No hubo premio

No hubo premio

No hubo premio

H. C. P. Dam (Dinamarca)

E. A. Doisy (U. S. A.)

J. Erlanger (U. S. A.)

H. S. Gasser (U. S. A.)

A. Fleming (Gran Bretaña)

H. W. Florey (Gran Bretaña)

E. B. Chain (Gran Bretaña)

H. J. Muller (U. S. A.)

C. F. Cori (U. S. A.)

G. T. Cori (U. S. A.)

B. A. Houssay (Argentina)

P. H. Müller (Suiza)

W. R. Hess (Suiza)

A. C. F. E. Moniz (Portugal)

E. C. Kendall (U. S. A.)

T. Reichstein (Suiza)

P. S. Hench (U. S. A.)

M. Theiler (Sur Africa)

S. A. Waksman (U. S. A.)

H. A. Krebs (Gran Bretaña)

F. A. Lipmann (U. S. A.)

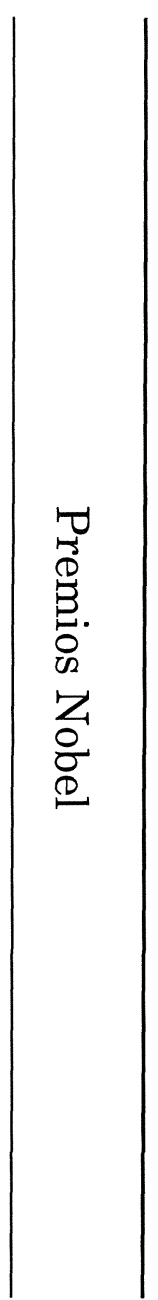

ம 


\section{Relación de Galardonados con el Premio Nobel (1901-2000)}

\begin{tabular}{|c|c|}
\hline AÑO & Física \\
\hline 1901 & W. C. Röntgen (Alemania) \\
\hline \multirow[t]{2}{*}{1902} & H. A. Lorentz (Holanda) \\
\hline & $\begin{array}{l}\text { P. Zeeman (Holanda) } \\
\text { H. A. Becquerel (Francia) }\end{array}$ \\
\hline \multirow{2}{*}{1903} & P. Curie (Francia) \\
\hline & Marie S. Curie (Francia) \\
\hline 1904 & Lord Rayleigh (Gran Bretaña) \\
\hline 1905 & P. E. A. von Lenard (Alemania) \\
\hline 1906 & J. J. Thomson (Gran Bretaña) \\
\hline 1907 & A. A. Michelson (U. S. A.) \\
\hline 1908 & G. Lippmann (Francia) \\
\hline \multirow[t]{2}{*}{1909} & G. Marconi (Italia) \\
\hline & C. F. Braun (Alemania) \\
\hline 1910 & J. D. van der Waals (Holanda) \\
\hline 1911 & W. Wien (Alemania) \\
\hline 1912 & N. G. Dalén (Suecia) \\
\hline 1913 & H. Kamerlingh Onnes (Holanda) \\
\hline 1914 & M. von Laue (Alemania) \\
\hline \multirow[t]{2}{*}{1915} & W. H. Bragg (Gran Bretaña) \\
\hline & W. L. Bragg (Gran Bretaña) \\
\hline 1916 & No hubo premio \\
\hline 1917 & C. G. Barkla (Gran Bretaña) \\
\hline 1918 & M. K. E. L. Planck (Alemania) \\
\hline 1919 & J. Stark (Alemania) \\
\hline 1920 & C. E. Guillaume (Suiza) \\
\hline
\end{tabular}

Química

J. H. van't Hoff (Holanda)

H. E. Fischer (Alemania)

S. A. Arrhenius (Suecia)

W. Ramsay (Gran Bretaña)

A. von Baeyer (Alemania)

H. Moissan (Francia)

E. Buchner (Alemania)

E. Rutherford (Gran Bretaña)

W. Ostwald (Alemania)

O. Wallach (Alemania)

Marie Curie (Francia)

V. Grignard (Francia)

P. Sabatier (Francia)

A. Werner (Suiza)

T. W. Richards (U. S. A.)

R. M. Willstätter (Alemania)

No hubo premio

No hubo premio

F. Haber (Alemania)

No hubo premio

W. H. Nernst (Alemania)
Fisiología y Medicina

E. A. von Behring (Alemania)

R. Ross (Gran Bretaña)

N. R. Finsen (Dinamarca)

I. P. Paulov (Rusia)

R. Koch (Alemania)

C. Golgi (Italia)

S. Ramón y Cajal (España)

C. L. A. Laveran (Francia)

P. Ehrlich (Alemania)

I. I. Metchnikov (Rusia)

E. T. Kocher (Suiza)

A. Kossel (Alemania)

A. Gullstrand (Suecia)

A. Carrel (U. S. A.)

C. R. Richet (Francia)

R. Bárány (Austria)

No hubo premio

No hubo premio

No hubo premio

No hubo premio

J. Bordet (Bélgica)

S. A. S. Krogh (Dinamarca) 
F. Sody (Gran Bretaña)

F. W. Aston (Gran Bretaña)

F. Pregl (Austria)

No hubo premio

R. A. Zsigmondy (Alemania)

T. Svedberg (Suecia)

H. O. Wieland (Alemania)

A. O. R. Windaus (Alemania)

A. Harden (Gran Bretaña)

H. K. A. S. von Euler (Suecia)

H. Fischer (Alemania)

C. Bosch (Alemania)

F. Bergius (Alemania)

I. Langmuir (U. S. A.)

No hubo premio

H. C. Urey (U. S. A.)

F. Joliot (Francia)

Irène Joliot-Curie (Francia)

P. J. W. Debye (Holanda)

W. N. Haworth (Gran Bretaña)

P. Karrer (Suiza)
No hubo premio

A. V. Hill (Gran Bretaña)

O. F. Meyerhof (Alemania)

F. G. Banting (Canada)

J. J. R. Macleod (Canada)

W. Einthoven (Holanda)

No hubo premio

J. A. G. Fibiger (Dinamarca)

J. Wagner-Jauregg (Austria)

C. J. H. Nicolle (Francia)

C. Eijkman (Holanda)

F. G. Hopkins (Gran Bretaña)

K. Landsteiner (Austria)

O. H. Warburg (Alemania)

C. S. Sherrington (Gran Bretaña)

E. D. Adrian (Gran Bretaña)

T. H. Morgan (U. S. A.)

G. H. Whipple (U. S. A.)

G. R. Minot (U. S. A.)

W. P. Murphy (U. S. A.)

H. Spemann (Alemania)

H. H. Dale (Gran Bretaña)

O. Loewi (Austria)

A. von Szent-Györgyi (Hungría) 


\begin{tabular}{|c|c|}
\hline AÑO & Física \\
\hline 1938 & E. Fermi (Italia) \\
\hline 1939 & E. O. Lawrence (U. S. A.) \\
\hline 1940 & No hubo premio \\
\hline 1941 & No hubo premio \\
\hline 1942 & No hubo premio \\
\hline 1943 & O. Stern (U. S. A.) \\
\hline 1944 & I. I. Rabi (U. S. A.) \\
\hline 1945 & W. Pauli (Austria) \\
\hline 1946 & P. W. Bridgman (U. S. A.) \\
\hline 1947 & E. V. Appleton (Gran Bretaña) \\
\hline 1948 & P. M. S. Blackett (Gran Bretaña) \\
\hline 1949 & H. Yukawa (Japón) \\
\hline 1950 & C. F. Powell (Gran Bretaña) \\
\hline 1951 & $\begin{array}{l}\text { J. D. Cockcroft (Gran Bretaña) } \\
\text { E. T. S. Walton (Irlanda) }\end{array}$ \\
\hline 1952 & $\begin{array}{l}\text { F. Bloch (U. S. A.) } \\
\text { E. M. Purcell (U. S. A.) }\end{array}$ \\
\hline 1953 & F. Zernike (Holanda) \\
\hline
\end{tabular}

Química

R. Kuhn (Alemania)

A. F. J. Butenandt (Alemania)

L. Ruzicka (Suiza)

No hubo premio

No hubo premio

No hubo premio

G. de Hevesy (Hungría)

O. Hahn (Alemania)

A. I. Virtanen (Finlandia)

J. B. Sumner (U. S. A.)

W. M. Stanley (U. S. A.)

J. H. Northrop (U. S. A.)

R. Robinson (Gran Bretaña)

A. W. K. Tiselius (Suecia)

W. F. Giauque (U. S. A.)

O. P. H. Diels (Alemania)

K. Alder (Alemania)

\section{E. M. McMillan (U. S. A.)}

G. T. Seaborg (U. S. A.)

A. J. P. Martin (Gran Bretaña)

R. L. M. Synge (Gran Bretaña)

H. Staudinger (Alemania)
Fisiología y Medicina

C. J. F. Heymans (Bélgica)

G. Domagk (Alemania)

No hubo premio

No hubo premio

No hubo premio

H. C. P. Dam (Dinamarca)

E. A. Doisy (U. S. A.)

J. Erlanger (U. S. A.)

H. S. Gasser (U. S. A.)

A. Fleming (Gran Bretaña)

H. W. Florey (Gran Bretaña)

E. B. Chain (Gran Bretaña)

H. J. Muller (U. S. A.)

C. F. Cori (U. S. A.)

G. T. Cori (U. S. A.)

B. A. Houssay (Argentina)

P. H. Müller (Suiza)

W. R. Hess (Suiza)

A. C. F. E. Moniz (Portugal)

E. C. Kendall (U. S. A.)

T. Reichstein (Suiza)

P. S. Hench (U. S. A.)

M. Theiler (Sur Africa)

S. A. Waksman (U. S. A.)

H. A. Krebs (Gran Bretaña)

F. A. Lipmann (U. S. A.)

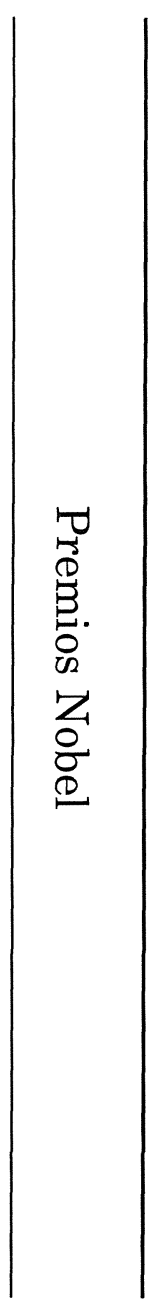

ம 


\section{Relación de Galardonados con el Premio Nobel (1901-2000)}

\begin{tabular}{|c|c|}
\hline AÑO & Física \\
\hline 1901 & W. C. Röntgen (Alemania) \\
\hline \multirow[t]{2}{*}{1902} & H. A. Lorentz (Holanda) \\
\hline & $\begin{array}{l}\text { P. Zeeman (Holanda) } \\
\text { H. A. Becquerel (Francia) }\end{array}$ \\
\hline \multirow{2}{*}{1903} & P. Curie (Francia) \\
\hline & Marie S. Curie (Francia) \\
\hline 1904 & Lord Rayleigh (Gran Bretaña) \\
\hline 1905 & P. E. A. von Lenard (Alemania) \\
\hline 1906 & J. J. Thomson (Gran Bretaña) \\
\hline 1907 & A. A. Michelson (U. S. A.) \\
\hline 1908 & G. Lippmann (Francia) \\
\hline \multirow[t]{2}{*}{1909} & G. Marconi (Italia) \\
\hline & C. F. Braun (Alemania) \\
\hline 1910 & J. D. van der Waals (Holanda) \\
\hline 1911 & W. Wien (Alemania) \\
\hline 1912 & N. G. Dalén (Suecia) \\
\hline 1913 & H. Kamerlingh Onnes (Holanda) \\
\hline 1914 & M. von Laue (Alemania) \\
\hline \multirow[t]{2}{*}{1915} & W. H. Bragg (Gran Bretaña) \\
\hline & W. L. Bragg (Gran Bretaña) \\
\hline 1916 & No hubo premio \\
\hline 1917 & C. G. Barkla (Gran Bretaña) \\
\hline 1918 & M. K. E. L. Planck (Alemania) \\
\hline 1919 & J. Stark (Alemania) \\
\hline 1920 & C. E. Guillaume (Suiza) \\
\hline
\end{tabular}

Química

J. H. van't Hoff (Holanda)

H. E. Fischer (Alemania)

S. A. Arrhenius (Suecia)

W. Ramsay (Gran Bretaña)

A. von Baeyer (Alemania)

H. Moissan (Francia)

E. Buchner (Alemania)

E. Rutherford (Gran Bretaña)

W. Ostwald (Alemania)

O. Wallach (Alemania)

Marie Curie (Francia)

V. Grignard (Francia)

P. Sabatier (Francia)

A. Werner (Suiza)

T. W. Richards (U. S. A.)

R. M. Willstätter (Alemania)

No hubo premio

No hubo premio

F. Haber (Alemania)

No hubo premio

W. H. Nernst (Alemania)
Fisiología y Medicina

E. A. von Behring (Alemania)

R. Ross (Gran Bretaña)

N. R. Finsen (Dinamarca)

I. P. Paulov (Rusia)

R. Koch (Alemania)

C. Golgi (Italia)

S. Ramón y Cajal (España)

C. L. A. Laveran (Francia)

P. Ehrlich (Alemania)

I. I. Metchnikov (Rusia)

E. T. Kocher (Suiza)

A. Kossel (Alemania)

A. Gullstrand (Suecia)

A. Carrel (U. S. A.)

C. R. Richet (Francia)

R. Bárány (Austria)

No hubo premio

No hubo premio

No hubo premio

No hubo premio

J. Bordet (Bélgica)

S. A. S. Krogh (Dinamarca) 
F. Sody (Gran Bretaña)

F. W. Aston (Gran Bretaña)

F. Pregl (Austria)

No hubo premio

R. A. Zsigmondy (Alemania)

T. Svedberg (Suecia)

H. O. Wieland (Alemania)

A. O. R. Windaus (Alemania)

A. Harden (Gran Bretaña)

H. K. A. S. von Euler (Suecia)

H. Fischer (Alemania)

C. Bosch (Alemania)

F. Bergius (Alemania)

I. Langmuir (U. S. A.)

No hubo premio

H. C. Urey (U. S. A.)

F. Joliot (Francia)

Irène Joliot-Curie (Francia)

P. J. W. Debye (Holanda)

W. N. Haworth (Gran Bretaña)

P. Karrer (Suiza)
No hubo premio

A. V. Hill (Gran Bretaña)

O. F. Meyerhof (Alemania)

F. G. Banting (Canada)

J. J. R. Macleod (Canada)

W. Einthoven (Holanda)

No hubo premio

J. A. G. Fibiger (Dinamarca)

J. Wagner-Jauregg (Austria)

C. J. H. Nicolle (Francia)

C. Eijkman (Holanda)

F. G. Hopkins (Gran Bretaña)

K. Landsteiner (Austria)

O. H. Warburg (Alemania)

C. S. Sherrington (Gran Bretaña)

E. D. Adrian (Gran Bretaña)

T. H. Morgan (U. S. A.)

G. H. Whipple (U. S. A.)

G. R. Minot (U. S. A.)

W. P. Murphy (U. S. A.)

H. Spemann (Alemania)

H. H. Dale (Gran Bretaña)

O. Loewi (Austria)

A. von Szent-Györgyi (Hungría) 


\begin{tabular}{|c|c|}
\hline AÑO & Física \\
\hline 1938 & E. Fermi (Italia) \\
\hline 1939 & E. O. Lawrence (U. S. A.) \\
\hline 1940 & No hubo premio \\
\hline 1941 & No hubo premio \\
\hline 1942 & No hubo premio \\
\hline 1943 & O. Stern (U. S. A.) \\
\hline 1944 & I. I. Rabi (U. S. A.) \\
\hline 1945 & W. Pauli (Austria) \\
\hline 1946 & P. W. Bridgman (U. S. A.) \\
\hline 1947 & E. V. Appleton (Gran Bretaña) \\
\hline 1948 & P. M. S. Blackett (Gran Bretaña) \\
\hline 1949 & H. Yukawa (Japón) \\
\hline 1950 & C. F. Powell (Gran Bretaña) \\
\hline 1951 & $\begin{array}{l}\text { J. D. Cockcroft (Gran Bretaña) } \\
\text { E. T. S. Walton (Irlanda) }\end{array}$ \\
\hline 1952 & $\begin{array}{l}\text { F. Bloch (U. S. A.) } \\
\text { E. M. Purcell (U. S. A.) }\end{array}$ \\
\hline 1953 & F. Zernike (Holanda) \\
\hline
\end{tabular}

Química

R. Kuhn (Alemania)

A. F. J. Butenandt (Alemania)

L. Ruzicka (Suiza)

No hubo premio

No hubo premio

No hubo premio

G. de Hevesy (Hungría)

O. Hahn (Alemania)

A. I. Virtanen (Finlandia)

J. B. Sumner (U. S. A.)

W. M. Stanley (U. S. A.)

J. H. Northrop (U. S. A.)

R. Robinson (Gran Bretaña)

A. W. K. Tiselius (Suecia)

W. F. Giauque (U. S. A.)

O. P. H. Diels (Alemania)

K. Alder (Alemania)

\section{E. M. McMillan (U. S. A.)}

G. T. Seaborg (U. S. A.)

A. J. P. Martin (Gran Bretaña)

R. L. M. Synge (Gran Bretaña)

H. Staudinger (Alemania)
Fisiología y Medicina

C. J. F. Heymans (Bélgica)

G. Domagk (Alemania)

No hubo premio

No hubo premio

No hubo premio

H. C. P. Dam (Dinamarca)

E. A. Doisy (U. S. A.)

J. Erlanger (U. S. A.)

H. S. Gasser (U. S. A.)

A. Fleming (Gran Bretaña)

H. W. Florey (Gran Bretaña)

E. B. Chain (Gran Bretaña)

H. J. Muller (U. S. A.)

C. F. Cori (U. S. A.)

G. T. Cori (U. S. A.)

B. A. Houssay (Argentina)

P. H. Müller (Suiza)

W. R. Hess (Suiza)

A. C. F. E. Moniz (Portugal)

E. C. Kendall (U. S. A.)

T. Reichstein (Suiza)

P. S. Hench (U. S. A.)

M. Theiler (Sur Africa)

S. A. Waksman (U. S. A.)

H. A. Krebs (Gran Bretaña)

F. A. Lipmann (U. S. A.)

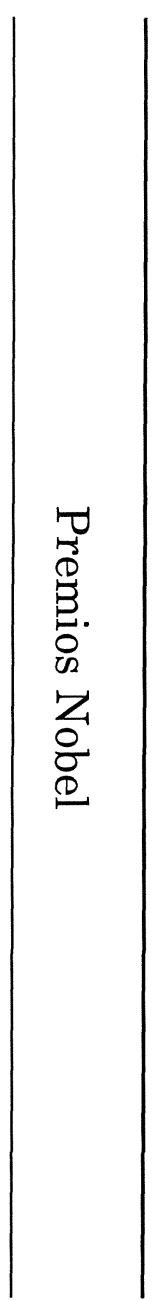

ம 


\begin{tabular}{|c|c|}
\hline AÑO & Física \\
\hline 1954 & $\begin{array}{l}\text { M. Born (Gran Bretaña) } \\
\text { W. Bothe (Almania) }\end{array}$ \\
\hline 1955 & $\begin{array}{l}\text { W. E. Lamb (Gran Bretaña) } \\
\text { P. Kusch (U. S. A.) }\end{array}$ \\
\hline 1956 & $\begin{array}{l}\text { W. B. Shockley (U. S. A.) } \\
\text { J. Bardeen (U. S. A.) } \\
\text { W. H. Brattain (U. S. A.) }\end{array}$ \\
\hline 1957 & $\begin{array}{l}\text { C. N. Yang (China) } \\
\text { T.D. Lee (China) }\end{array}$ \\
\hline 1958 & $\begin{array}{l}\text { P. A. Cherenkov (Rusia) } \\
\text { I. M. Frank (Rusia) } \\
\text { I. Y. Tamm (Rusia) }\end{array}$ \\
\hline 1959 & $\begin{array}{l}\text { E. G. Segrè (U. S. A.) } \\
\text { O. Chamberlain (U. S. A.) }\end{array}$ \\
\hline 1960 & D. A. Glaser (U. S. A.) \\
\hline 1961 & $\begin{array}{l}\text { R. Hofstadter (U. S. A.) } \\
\text { R. L. Mössbauer (Alemania) }\end{array}$ \\
\hline 1962 & L. D. Landau (Rusia) \\
\hline 1963 & $\begin{array}{l}\text { E. P. Wigner (U. S. A.) } \\
\text { M. Goeppert-Mayer (U. S. A.) } \\
\text { J. H. D. Jensen (Alemania) }\end{array}$ \\
\hline 1964 & $\begin{array}{l}\text { C. H. Townes (U. S. A.) } \\
\text { N. G. Basov (Rusia) } \\
\text { A. M. Prokhorov (Rusia) }\end{array}$ \\
\hline 1965 & $\begin{array}{l}\text { A-T. Tomonaga (Japón) } \\
\text { J. Schwinger (U. S. A.) } \\
\text { R. P. Feyman (U. S. A.) }\end{array}$ \\
\hline 1966 & A. Kastler (Francia) \\
\hline
\end{tabular}

\section{Química}

L. C. Pauling (U. S. A.)

V. du Vigneaud (U. S. A.)

C. N. Hinshelwood (Gran Bretaña)

N. N. Semenov (Rusia)

A. R. Todd (Gran Bretaña)

F. Sanger (Gran Bretaña)

J. Heyrovsky (Checoslovaquia)

W. F. Libby (U. S. A.)

M. Calvin (U. S. A.)

M. F. Perutz (Gran Bretaña)

J. C. Kendrew (Gran Bretaña)

K. Ziegler (Alemania)

G. Natta (Italia)

D. C. Hodgkin (Gran Bretaña)

R. B. Woodward (U. S. A.)

R. S. Mulliken (U. S. A.)

\section{Fisiología y Medicina}

J. F. Enders (U. S. A.)

T. H. Weller (U. S. A.)

F. C. Robbins (U. S. A.)

A. H. T. Theorel (Suecia)

A. F. Cournand (U. S. A.)

W. Forssmann (Alemania)

D. W. Richards (U. S. A.)

D. Bovet (Italia)

G. W. Beadle (U. S. A.)

E. L. Tatum (U. S. A.)

J. Lederberg (U. S. A.)

S. Ochoa (U. S. A.)

A. Kornberg (U. S. A.)

F. M. Burnet (Australia)

P. B. Medawar (Gran Bretaña)

G. von Békésy (U. S. A.)

F. H. C. Crick (Gran Bretaña) J. D. Watson (U. S. A.)

M. H. F. Wilkins (Gran Bretaña)

J. C. Eccles (Australia)

A. L. Hodgkin (Gran Bretaña)

A. F. Huxley (Gran Bretaña)

K. Bloch (U. S. A.)

F. Lynen (Alemania)

F. Jacob (Francia)

A. Lwoff (Francia)

J. Monod (Francia)

P. Rous (U. S. A.)

C. B. Huggins (U. S. A.) 
F. Sody (Gran Bretaña)

F. W. Aston (Gran Bretaña)

F. Pregl (Austria)

No hubo premio

R. A. Zsigmondy (Alemania)

T. Svedberg (Suecia)

H. O. Wieland (Alemania)

A. O. R. Windaus (Alemania)

A. Harden (Gran Bretaña)

H. K. A. S. von Euler (Suecia)

H. Fischer (Alemania)

C. Bosch (Alemania)

F. Bergius (Alemania)

I. Langmuir (U. S. A.)

No hubo premio

H. C. Urey (U. S. A.)

F. Joliot (Francia)

Irène Joliot-Curie (Francia)

P. J. W. Debye (Holanda)

W. N. Haworth (Gran Bretaña)

P. Karrer (Suiza)
No hubo premio

A. V. Hill (Gran Bretaña)

O. F. Meyerhof (Alemania)

F. G. Banting (Canada)

J. J. R. Macleod (Canada)

W. Einthoven (Holanda)

No hubo premio

J. A. G. Fibiger (Dinamarca)

J. Wagner-Jauregg (Austria)

C. J. H. Nicolle (Francia)

C. Eijkman (Holanda)

F. G. Hopkins (Gran Bretaña)

K. Landsteiner (Austria)

O. H. Warburg (Alemania)

C. S. Sherrington (Gran Bretaña)

E. D. Adrian (Gran Bretaña)

T. H. Morgan (U. S. A.)

G. H. Whipple (U. S. A.)

G. R. Minot (U. S. A.)

W. P. Murphy (U. S. A.)

H. Spemann (Alemania)

H. H. Dale (Gran Bretaña)

O. Loewi (Austria)

A. von Szent-Györgyi (Hungría) 


\begin{tabular}{|c|c|}
\hline AÑO & Física \\
\hline 1938 & E. Fermi (Italia) \\
\hline 1939 & E. O. Lawrence (U. S. A.) \\
\hline 1940 & No hubo premio \\
\hline 1941 & No hubo premio \\
\hline 1942 & No hubo premio \\
\hline 1943 & O. Stern (U. S. A.) \\
\hline 1944 & I. I. Rabi (U. S. A.) \\
\hline 1945 & W. Pauli (Austria) \\
\hline 1946 & P. W. Bridgman (U. S. A.) \\
\hline 1947 & E. V. Appleton (Gran Bretaña) \\
\hline 1948 & P. M. S. Blackett (Gran Bretaña) \\
\hline 1949 & H. Yukawa (Japón) \\
\hline 1950 & C. F. Powell (Gran Bretaña) \\
\hline 1951 & $\begin{array}{l}\text { J. D. Cockcroft (Gran Bretaña) } \\
\text { E. T. S. Walton (Irlanda) }\end{array}$ \\
\hline 1952 & $\begin{array}{l}\text { F. Bloch (U. S. A.) } \\
\text { E. M. Purcell (U. S. A.) }\end{array}$ \\
\hline 1953 & F. Zernike (Holanda) \\
\hline
\end{tabular}

Química

R. Kuhn (Alemania)

A. F. J. Butenandt (Alemania)

L. Ruzicka (Suiza)

No hubo premio

No hubo premio

No hubo premio

G. de Hevesy (Hungría)

O. Hahn (Alemania)

A. I. Virtanen (Finlandia)

J. B. Sumner (U. S. A.)

W. M. Stanley (U. S. A.)

J. H. Northrop (U. S. A.)

R. Robinson (Gran Bretaña)

A. W. K. Tiselius (Suecia)

W. F. Giauque (U. S. A.)

O. P. H. Diels (Alemania)

K. Alder (Alemania)

\section{E. M. McMillan (U. S. A.)}

G. T. Seaborg (U. S. A.)

A. J. P. Martin (Gran Bretaña)

R. L. M. Synge (Gran Bretaña)

H. Staudinger (Alemania)
Fisiología y Medicina

C. J. F. Heymans (Bélgica)

G. Domagk (Alemania)

No hubo premio

No hubo premio

No hubo premio

H. C. P. Dam (Dinamarca)

E. A. Doisy (U. S. A.)

J. Erlanger (U. S. A.)

H. S. Gasser (U. S. A.)

A. Fleming (Gran Bretaña)

H. W. Florey (Gran Bretaña)

E. B. Chain (Gran Bretaña)

H. J. Muller (U. S. A.)

C. F. Cori (U. S. A.)

G. T. Cori (U. S. A.)

B. A. Houssay (Argentina)

P. H. Müller (Suiza)

W. R. Hess (Suiza)

A. C. F. E. Moniz (Portugal)

E. C. Kendall (U. S. A.)

T. Reichstein (Suiza)

P. S. Hench (U. S. A.)

M. Theiler (Sur Africa)

S. A. Waksman (U. S. A.)

H. A. Krebs (Gran Bretaña)

F. A. Lipmann (U. S. A.)

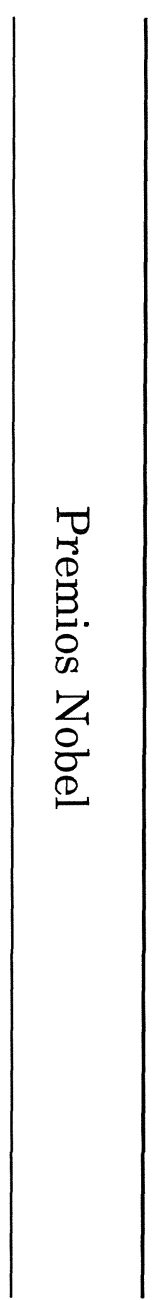

ம 


\section{Relación de Galardonados con el Premio Nobel (1901-2000)}

\begin{tabular}{|c|c|}
\hline AÑO & Física \\
\hline 1901 & W. C. Röntgen (Alemania) \\
\hline \multirow[t]{2}{*}{1902} & H. A. Lorentz (Holanda) \\
\hline & $\begin{array}{l}\text { P. Zeeman (Holanda) } \\
\text { H. A. Becquerel (Francia) }\end{array}$ \\
\hline \multirow{2}{*}{1903} & P. Curie (Francia) \\
\hline & Marie S. Curie (Francia) \\
\hline 1904 & Lord Rayleigh (Gran Bretaña) \\
\hline 1905 & P. E. A. von Lenard (Alemania) \\
\hline 1906 & J. J. Thomson (Gran Bretaña) \\
\hline 1907 & A. A. Michelson (U. S. A.) \\
\hline 1908 & G. Lippmann (Francia) \\
\hline \multirow[t]{2}{*}{1909} & G. Marconi (Italia) \\
\hline & C. F. Braun (Alemania) \\
\hline 1910 & J. D. van der Waals (Holanda) \\
\hline 1911 & W. Wien (Alemania) \\
\hline 1912 & N. G. Dalén (Suecia) \\
\hline 1913 & H. Kamerlingh Onnes (Holanda) \\
\hline 1914 & M. von Laue (Alemania) \\
\hline \multirow[t]{2}{*}{1915} & W. H. Bragg (Gran Bretaña) \\
\hline & W. L. Bragg (Gran Bretaña) \\
\hline 1916 & No hubo premio \\
\hline 1917 & C. G. Barkla (Gran Bretaña) \\
\hline 1918 & M. K. E. L. Planck (Alemania) \\
\hline 1919 & J. Stark (Alemania) \\
\hline 1920 & C. E. Guillaume (Suiza) \\
\hline
\end{tabular}

Química

J. H. van't Hoff (Holanda)

H. E. Fischer (Alemania)

S. A. Arrhenius (Suecia)

W. Ramsay (Gran Bretaña)

A. von Baeyer (Alemania)

H. Moissan (Francia)

E. Buchner (Alemania)

E. Rutherford (Gran Bretaña)

W. Ostwald (Alemania)

O. Wallach (Alemania)

Marie Curie (Francia)

V. Grignard (Francia)

P. Sabatier (Francia)

A. Werner (Suiza)

T. W. Richards (U. S. A.)

R. M. Willstätter (Alemania)

No hubo premio

No hubo premio

F. Haber (Alemania)

No hubo premio

W. H. Nernst (Alemania)
Fisiología y Medicina

E. A. von Behring (Alemania)

R. Ross (Gran Bretaña)

N. R. Finsen (Dinamarca)

I. P. Paulov (Rusia)

R. Koch (Alemania)

C. Golgi (Italia)

S. Ramón y Cajal (España)

C. L. A. Laveran (Francia)

P. Ehrlich (Alemania)

I. I. Metchnikov (Rusia)

E. T. Kocher (Suiza)

A. Kossel (Alemania)

A. Gullstrand (Suecia)

A. Carrel (U. S. A.)

C. R. Richet (Francia)

R. Bárány (Austria)

No hubo premio

No hubo premio

No hubo premio

No hubo premio

J. Bordet (Bélgica)

S. A. S. Krogh (Dinamarca) 
F. Sody (Gran Bretaña)

F. W. Aston (Gran Bretaña)

F. Pregl (Austria)

No hubo premio

R. A. Zsigmondy (Alemania)

T. Svedberg (Suecia)

H. O. Wieland (Alemania)

A. O. R. Windaus (Alemania)

A. Harden (Gran Bretaña)

H. K. A. S. von Euler (Suecia)

H. Fischer (Alemania)

C. Bosch (Alemania)

F. Bergius (Alemania)

I. Langmuir (U. S. A.)

No hubo premio

H. C. Urey (U. S. A.)

F. Joliot (Francia)

Irène Joliot-Curie (Francia)

P. J. W. Debye (Holanda)

W. N. Haworth (Gran Bretaña)

P. Karrer (Suiza)
No hubo premio

A. V. Hill (Gran Bretaña)

O. F. Meyerhof (Alemania)

F. G. Banting (Canada)

J. J. R. Macleod (Canada)

W. Einthoven (Holanda)

No hubo premio

J. A. G. Fibiger (Dinamarca)

J. Wagner-Jauregg (Austria)

C. J. H. Nicolle (Francia)

C. Eijkman (Holanda)

F. G. Hopkins (Gran Bretaña)

K. Landsteiner (Austria)

O. H. Warburg (Alemania)

C. S. Sherrington (Gran Bretaña)

E. D. Adrian (Gran Bretaña)

T. H. Morgan (U. S. A.)

G. H. Whipple (U. S. A.)

G. R. Minot (U. S. A.)

W. P. Murphy (U. S. A.)

H. Spemann (Alemania)

H. H. Dale (Gran Bretaña)

O. Loewi (Austria)

A. von Szent-Györgyi (Hungría) 


\begin{tabular}{|c|c|}
\hline AÑO & Física \\
\hline 1938 & E. Fermi (Italia) \\
\hline 1939 & E. O. Lawrence (U. S. A.) \\
\hline 1940 & No hubo premio \\
\hline 1941 & No hubo premio \\
\hline 1942 & No hubo premio \\
\hline 1943 & O. Stern (U. S. A.) \\
\hline 1944 & I. I. Rabi (U. S. A.) \\
\hline 1945 & W. Pauli (Austria) \\
\hline 1946 & P. W. Bridgman (U. S. A.) \\
\hline 1947 & E. V. Appleton (Gran Bretaña) \\
\hline 1948 & P. M. S. Blackett (Gran Bretaña) \\
\hline 1949 & H. Yukawa (Japón) \\
\hline 1950 & C. F. Powell (Gran Bretaña) \\
\hline 1951 & $\begin{array}{l}\text { J. D. Cockcroft (Gran Bretaña) } \\
\text { E. T. S. Walton (Irlanda) }\end{array}$ \\
\hline 1952 & $\begin{array}{l}\text { F. Bloch (U. S. A.) } \\
\text { E. M. Purcell (U. S. A.) }\end{array}$ \\
\hline 1953 & F. Zernike (Holanda) \\
\hline
\end{tabular}

Química

R. Kuhn (Alemania)

A. F. J. Butenandt (Alemania)

L. Ruzicka (Suiza)

No hubo premio

No hubo premio

No hubo premio

G. de Hevesy (Hungría)

O. Hahn (Alemania)

A. I. Virtanen (Finlandia)

J. B. Sumner (U. S. A.)

W. M. Stanley (U. S. A.)

J. H. Northrop (U. S. A.)

R. Robinson (Gran Bretaña)

A. W. K. Tiselius (Suecia)

W. F. Giauque (U. S. A.)

O. P. H. Diels (Alemania)

K. Alder (Alemania)

\section{E. M. McMillan (U. S. A.)}

G. T. Seaborg (U. S. A.)

A. J. P. Martin (Gran Bretaña)

R. L. M. Synge (Gran Bretaña)

H. Staudinger (Alemania)
Fisiología y Medicina

C. J. F. Heymans (Bélgica)

G. Domagk (Alemania)

No hubo premio

No hubo premio

No hubo premio

H. C. P. Dam (Dinamarca)

E. A. Doisy (U. S. A.)

J. Erlanger (U. S. A.)

H. S. Gasser (U. S. A.)

A. Fleming (Gran Bretaña)

H. W. Florey (Gran Bretaña)

E. B. Chain (Gran Bretaña)

H. J. Muller (U. S. A.)

C. F. Cori (U. S. A.)

G. T. Cori (U. S. A.)

B. A. Houssay (Argentina)

P. H. Müller (Suiza)

W. R. Hess (Suiza)

A. C. F. E. Moniz (Portugal)

E. C. Kendall (U. S. A.)

T. Reichstein (Suiza)

P. S. Hench (U. S. A.)

M. Theiler (Sur Africa)

S. A. Waksman (U. S. A.)

H. A. Krebs (Gran Bretaña)

F. A. Lipmann (U. S. A.)

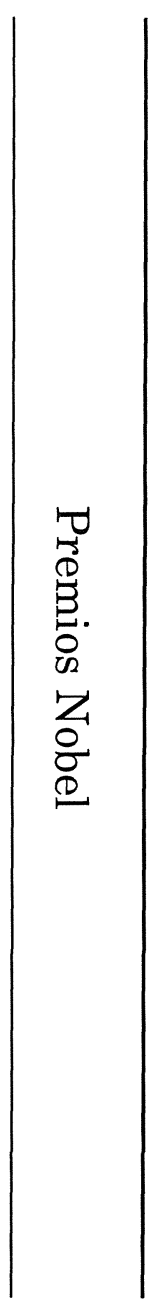

ம 


\section{Relación de Galardonados con el Premio Nobel (1901-2000)}

\begin{tabular}{|c|c|}
\hline AÑO & Física \\
\hline 1901 & W. C. Röntgen (Alemania) \\
\hline \multirow[t]{2}{*}{1902} & H. A. Lorentz (Holanda) \\
\hline & $\begin{array}{l}\text { P. Zeeman (Holanda) } \\
\text { H. A. Becquerel (Francia) }\end{array}$ \\
\hline \multirow{2}{*}{1903} & P. Curie (Francia) \\
\hline & Marie S. Curie (Francia) \\
\hline 1904 & Lord Rayleigh (Gran Bretaña) \\
\hline 1905 & P. E. A. von Lenard (Alemania) \\
\hline 1906 & J. J. Thomson (Gran Bretaña) \\
\hline 1907 & A. A. Michelson (U. S. A.) \\
\hline 1908 & G. Lippmann (Francia) \\
\hline \multirow[t]{2}{*}{1909} & G. Marconi (Italia) \\
\hline & C. F. Braun (Alemania) \\
\hline 1910 & J. D. van der Waals (Holanda) \\
\hline 1911 & W. Wien (Alemania) \\
\hline 1912 & N. G. Dalén (Suecia) \\
\hline 1913 & H. Kamerlingh Onnes (Holanda) \\
\hline 1914 & M. von Laue (Alemania) \\
\hline \multirow[t]{2}{*}{1915} & W. H. Bragg (Gran Bretaña) \\
\hline & W. L. Bragg (Gran Bretaña) \\
\hline 1916 & No hubo premio \\
\hline 1917 & C. G. Barkla (Gran Bretaña) \\
\hline 1918 & M. K. E. L. Planck (Alemania) \\
\hline 1919 & J. Stark (Alemania) \\
\hline 1920 & C. E. Guillaume (Suiza) \\
\hline
\end{tabular}

Química

J. H. van't Hoff (Holanda)

H. E. Fischer (Alemania)

S. A. Arrhenius (Suecia)

W. Ramsay (Gran Bretaña)

A. von Baeyer (Alemania)

H. Moissan (Francia)

E. Buchner (Alemania)

E. Rutherford (Gran Bretaña)

W. Ostwald (Alemania)

O. Wallach (Alemania)

Marie Curie (Francia)

V. Grignard (Francia)

P. Sabatier (Francia)

A. Werner (Suiza)

T. W. Richards (U. S. A.)

R. M. Willstätter (Alemania)

No hubo premio

No hubo premio

F. Haber (Alemania)

No hubo premio

W. H. Nernst (Alemania)
Fisiología y Medicina

E. A. von Behring (Alemania)

R. Ross (Gran Bretaña)

N. R. Finsen (Dinamarca)

I. P. Paulov (Rusia)

R. Koch (Alemania)

C. Golgi (Italia)

S. Ramón y Cajal (España)

C. L. A. Laveran (Francia)

P. Ehrlich (Alemania)

I. I. Metchnikov (Rusia)

E. T. Kocher (Suiza)

A. Kossel (Alemania)

A. Gullstrand (Suecia)

A. Carrel (U. S. A.)

C. R. Richet (Francia)

R. Bárány (Austria)

No hubo premio

No hubo premio

No hubo premio

No hubo premio

J. Bordet (Bélgica)

S. A. S. Krogh (Dinamarca) 
F. Sody (Gran Bretaña)

F. W. Aston (Gran Bretaña)

F. Pregl (Austria)

No hubo premio

R. A. Zsigmondy (Alemania)

T. Svedberg (Suecia)

H. O. Wieland (Alemania)

A. O. R. Windaus (Alemania)

A. Harden (Gran Bretaña)

H. K. A. S. von Euler (Suecia)

H. Fischer (Alemania)

C. Bosch (Alemania)

F. Bergius (Alemania)

I. Langmuir (U. S. A.)

No hubo premio

H. C. Urey (U. S. A.)

F. Joliot (Francia)

Irène Joliot-Curie (Francia)

P. J. W. Debye (Holanda)

W. N. Haworth (Gran Bretaña)

P. Karrer (Suiza)
No hubo premio

A. V. Hill (Gran Bretaña)

O. F. Meyerhof (Alemania)

F. G. Banting (Canada)

J. J. R. Macleod (Canada)

W. Einthoven (Holanda)

No hubo premio

J. A. G. Fibiger (Dinamarca)

J. Wagner-Jauregg (Austria)

C. J. H. Nicolle (Francia)

C. Eijkman (Holanda)

F. G. Hopkins (Gran Bretaña)

K. Landsteiner (Austria)

O. H. Warburg (Alemania)

C. S. Sherrington (Gran Bretaña)

E. D. Adrian (Gran Bretaña)

T. H. Morgan (U. S. A.)

G. H. Whipple (U. S. A.)

G. R. Minot (U. S. A.)

W. P. Murphy (U. S. A.)

H. Spemann (Alemania)

H. H. Dale (Gran Bretaña)

O. Loewi (Austria)

A. von Szent-Györgyi (Hungría) 


\begin{tabular}{|c|c|}
\hline AÑO & Física \\
\hline 1938 & E. Fermi (Italia) \\
\hline 1939 & E. O. Lawrence (U. S. A.) \\
\hline 1940 & No hubo premio \\
\hline 1941 & No hubo premio \\
\hline 1942 & No hubo premio \\
\hline 1943 & O. Stern (U. S. A.) \\
\hline 1944 & I. I. Rabi (U. S. A.) \\
\hline 1945 & W. Pauli (Austria) \\
\hline 1946 & P. W. Bridgman (U. S. A.) \\
\hline 1947 & E. V. Appleton (Gran Bretaña) \\
\hline 1948 & P. M. S. Blackett (Gran Bretaña) \\
\hline 1949 & H. Yukawa (Japón) \\
\hline 1950 & C. F. Powell (Gran Bretaña) \\
\hline 1951 & $\begin{array}{l}\text { J. D. Cockcroft (Gran Bretaña) } \\
\text { E. T. S. Walton (Irlanda) }\end{array}$ \\
\hline 1952 & $\begin{array}{l}\text { F. Bloch (U. S. A.) } \\
\text { E. M. Purcell (U. S. A.) }\end{array}$ \\
\hline 1953 & F. Zernike (Holanda) \\
\hline
\end{tabular}

Química

R. Kuhn (Alemania)

A. F. J. Butenandt (Alemania)

L. Ruzicka (Suiza)

No hubo premio

No hubo premio

No hubo premio

G. de Hevesy (Hungría)

O. Hahn (Alemania)

A. I. Virtanen (Finlandia)

J. B. Sumner (U. S. A.)

W. M. Stanley (U. S. A.)

J. H. Northrop (U. S. A.)

R. Robinson (Gran Bretaña)

A. W. K. Tiselius (Suecia)

W. F. Giauque (U. S. A.)

O. P. H. Diels (Alemania)

K. Alder (Alemania)

\section{E. M. McMillan (U. S. A.)}

G. T. Seaborg (U. S. A.)

A. J. P. Martin (Gran Bretaña)

R. L. M. Synge (Gran Bretaña)

H. Staudinger (Alemania)
Fisiología y Medicina

C. J. F. Heymans (Bélgica)

G. Domagk (Alemania)

No hubo premio

No hubo premio

No hubo premio

H. C. P. Dam (Dinamarca)

E. A. Doisy (U. S. A.)

J. Erlanger (U. S. A.)

H. S. Gasser (U. S. A.)

A. Fleming (Gran Bretaña)

H. W. Florey (Gran Bretaña)

E. B. Chain (Gran Bretaña)

H. J. Muller (U. S. A.)

C. F. Cori (U. S. A.)

G. T. Cori (U. S. A.)

B. A. Houssay (Argentina)

P. H. Müller (Suiza)

W. R. Hess (Suiza)

A. C. F. E. Moniz (Portugal)

E. C. Kendall (U. S. A.)

T. Reichstein (Suiza)

P. S. Hench (U. S. A.)

M. Theiler (Sur Africa)

S. A. Waksman (U. S. A.)

H. A. Krebs (Gran Bretaña)

F. A. Lipmann (U. S. A.)

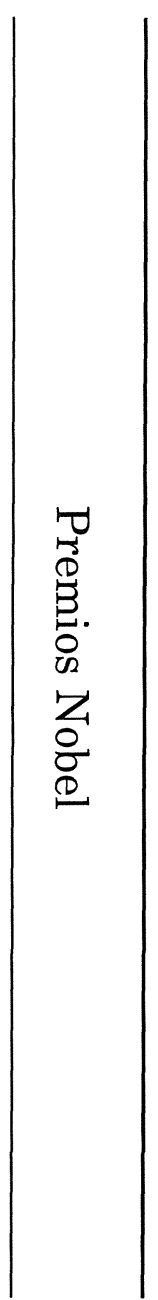

ம 


\begin{tabular}{|c|c|}
\hline AÑO & Física \\
\hline 1954 & $\begin{array}{l}\text { M. Born (Gran Bretaña) } \\
\text { W. Bothe (Almania) }\end{array}$ \\
\hline 1955 & $\begin{array}{l}\text { W. E. Lamb (Gran Bretaña) } \\
\text { P. Kusch (U. S. A.) }\end{array}$ \\
\hline 1956 & $\begin{array}{l}\text { W. B. Shockley (U. S. A.) } \\
\text { J. Bardeen (U. S. A.) } \\
\text { W. H. Brattain (U. S. A.) }\end{array}$ \\
\hline 1957 & $\begin{array}{l}\text { C. N. Yang (China) } \\
\text { T.D. Lee (China) }\end{array}$ \\
\hline 1958 & $\begin{array}{l}\text { P. A. Cherenkov (Rusia) } \\
\text { I. M. Frank (Rusia) } \\
\text { I. Y. Tamm (Rusia) }\end{array}$ \\
\hline 1959 & $\begin{array}{l}\text { E. G. Segrè (U. S. A.) } \\
\text { O. Chamberlain (U. S. A.) }\end{array}$ \\
\hline 1960 & D. A. Glaser (U. S. A.) \\
\hline 1961 & $\begin{array}{l}\text { R. Hofstadter (U. S. A.) } \\
\text { R. L. Mössbauer (Alemania) }\end{array}$ \\
\hline 1962 & L. D. Landau (Rusia) \\
\hline 1963 & $\begin{array}{l}\text { E. P. Wigner (U. S. A.) } \\
\text { M. Goeppert-Mayer (U. S. A.) } \\
\text { J. H. D. Jensen (Alemania) }\end{array}$ \\
\hline 1964 & $\begin{array}{l}\text { C. H. Townes (U. S. A.) } \\
\text { N. G. Basov (Rusia) } \\
\text { A. M. Prokhorov (Rusia) }\end{array}$ \\
\hline 1965 & $\begin{array}{l}\text { A-T. Tomonaga (Japón) } \\
\text { J. Schwinger (U. S. A.) } \\
\text { R. P. Feyman (U. S. A.) }\end{array}$ \\
\hline 1966 & A. Kastler (Francia) \\
\hline
\end{tabular}

\section{Química}

L. C. Pauling (U. S. A.)

V. du Vigneaud (U. S. A.)

C. N. Hinshelwood (Gran Bretaña)

N. N. Semenov (Rusia)

A. R. Todd (Gran Bretaña)

F. Sanger (Gran Bretaña)

J. Heyrovsky (Checoslovaquia)

W. F. Libby (U. S. A.)

M. Calvin (U. S. A.)

M. F. Perutz (Gran Bretaña)

J. C. Kendrew (Gran Bretaña)

K. Ziegler (Alemania)

G. Natta (Italia)

D. C. Hodgkin (Gran Bretaña)

R. B. Woodward (U. S. A.)

R. S. Mulliken (U. S. A.)

\section{Fisiología y Medicina}

J. F. Enders (U. S. A.)

T. H. Weller (U. S. A.)

F. C. Robbins (U. S. A.)

A. H. T. Theorel (Suecia)

A. F. Cournand (U. S. A.)

W. Forssmann (Alemania)

D. W. Richards (U. S. A.)

D. Bovet (Italia)

G. W. Beadle (U. S. A.)

E. L. Tatum (U. S. A.)

J. Lederberg (U. S. A.)

S. Ochoa (U. S. A.)

A. Kornberg (U. S. A.)

F. M. Burnet (Australia)

P. B. Medawar (Gran Bretaña)

G. von Békésy (U. S. A.)

F. H. C. Crick (Gran Bretaña) J. D. Watson (U. S. A.)

M. H. F. Wilkins (Gran Bretaña)

J. C. Eccles (Australia)

A. L. Hodgkin (Gran Bretaña)

A. F. Huxley (Gran Bretaña)

K. Bloch (U. S. A.)

F. Lynen (Alemania)

F. Jacob (Francia)

A. Lwoff (Francia)

J. Monod (Francia)

P. Rous (U. S. A.)

C. B. Huggins (U. S. A.) 
AÑO

D. Gabor (Gran Bretaña)

L. N. Copper (U. S. A.)

J. R. Schrieffer (U. S. A.)

1973

L. Esaki (Japón)

I. Giaever (U. S. A.)

B. D. Josephson (Gran Bretaña)

1974 M. Ryle (Gran Bretaña)

A. Hewish (Gran Bretaña)

1975

A. N. Bohr (Dinamarca)

B. R. Mottelson (Dinamarca)

L. J. Rainwater (U. S. A.)

1976

Richter (U. S. A.)

S. C. C. Ting (U. S. A.)

1977

N. F. Mott (Gran Bretaña)

J. H. van Vleck (U. S. A.)

\section{Química}

M. Eigen (U. S. A.)

R. G. W. Norrish (Gran Bretaña)

G. Porter (Gran Bretaña)

L. Onsager (U. S. A.)

D. H. R. Barton (Gran Bretaña)

O. Hassel (Noruega)

L. F. Leloir (Argentina)

G. Herzberg (Canada)

C. B. Anfinsen (U. S. A.)

S. Moore (U. S. A.)

W. H. Stein (U. S. A.)

E. O. Fischer (Alemania)

G. Wilkinson (Gran Bretaña)

P. J. Flory (U. S. A.)

J. W. Cornforth (Australia)

V. Prelog (Suiza)

W. N. Lipscomb (U. S. A.)

I. Prigogine (Bélgica)

\section{Fisiología y Medicina}

R. Granit (Suecia)

H. K. Hartline (U. S. A.)

G. Wald (U. S. A.)

R. W. Holley (U. S. A.)

H. G. Khorana (U. S. A.)

M. W. Nirenberg (U. S. A.)

M. Delbrück (U. S. A.)

A. D. Hershey (U. S. A.)

S. E. Luria (U. S. A.)

B. Katz (Gran Bretaña)

U. von Euler (Suecia)

J. Axelrod (U. S. A.)

E. W. Sutherland, Jr. (Gran Bretaña)

G. M. Edelman (U. S. A.)

R. R. Porter (Gran Bretaña)

K. von Frisch (Alemania)

K. Lorenz (Austria)

N. Tinbergen (Países Bajos)

A. Claude (U. S. A.)

C. de Duve (Bélgica)

G. E. Palade (U. S. A.)

D. Baltimore (U. S. A.)

R. Dulbecco (U. S. A.)

H. M. Temin (U. S. A.)

B. S. Blumberg (U. S. A.)

D. C. Gajdusek (U. S. A.)

R. Guillemin (U. S. A.)

A. V. Schally (U. S. A.)

R. Yalow (U. S. A.)

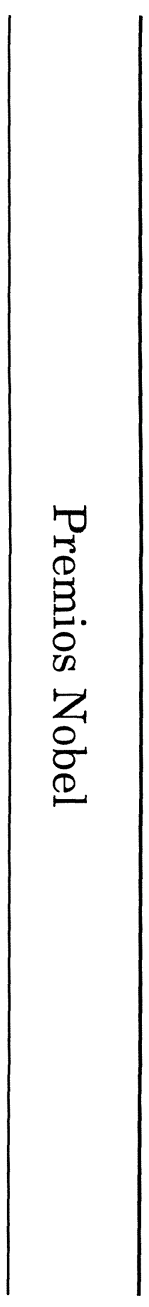

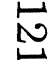


A. A. Penzias (U. S. A.)

R. W. Wilson (U. S. A.)

1979

S. L. Glashow (U. S. A.)

A. Salam (Pakistan)

S. Weinberg (U. S. A.)

1980

J. W. Cronin (U. S. A.)

V. L. Fitch (U. S. A.)

1981

N. Bloembergen (U. S. A.)

A. L. Schawlow (U. S. A.)

K. M. Siegbahn (Suecia)

$1982 \quad$ K. G. Wilson (U. S. A.)

1983 S. Chandrasekhar (U. S. A.)

W. A. Fowler (U. S. A.)

$1984 \quad$ C. Rubbia (Italia)

S. van der Meer (Holanda)

1985

K. von Klitzing (Alemania)

1986

E. Ruska (Alemania)

G. Binnig (Alemania)

H. Rohrer (Suiza)

1987

J. G. Bednorz (Alemania)

K. A. Müller (Suiza)

1988
Química

P. D. Mitchell (Gran Bretaña)

H. C. Brown (U. S. A.)

G. Wittig (Alemania)

P. Berg (U. S. A.)

W. Gilbert (U. S. A.)

F. Sanger (Gran Bretaña)

K. Fukui (Japón)

R. Hoffmann (U. S. A.)

A. Klug (Gran Bretaña)

H. Taube (U. S. A.)

R. B. Merrifield (U. S. A.)

H. A. Hauptman (U. S. A.

J. Karle (U. S. A.)

D. R. Herschbach (U. S. A.)

Y. T. Lee (U. S. A.)

J. C. Polanyi (Canada)

D. J. Cram (U. S. A )

J. M. Lehn (Francia)

C. J. Pedersen (U. S. A.)

J. Deisenhofer (Alemania)

R. Huber (Alemania)

H. Michel (Alemania)
Fisiología y Medicina

W. Arber (Suiza)

D. Nathans (U. S. A.)

H. O. Smith (U. S. A.)

A. M. Cormack (U. S. A.)

G. N. Hounsfield (Gran Bretaña)

B. Benacerraf (U. S. A.)

J. Dausset (Francia)

G. D. Snell (U. S. A.)

R. W. Sperry (U. S. A.)

D. H. Hubel (U. S. A.)

T. N. Wiesel (Suecia)

S. K. Bergström (Suecia)

B. I. Samuelsson (Suecia)

J. R. Vane (Gran Bretaña)

B. McClintock (U. S. A.)

N. K. Jerne (Dinamarca)

G. F. F. Köhler (Alemania)

C. Milstein (Gran Bretaña)

M. S. Brown (U. S. A.)

J. L. Goldstein (U. S. A.)

S. Cohen (U. S. A.)

R. Levi-Montalcini (U. S. A.)

S. Tonegawa (Japón)

W. Black (Gran Bretaña)

G. B. Elion (U. S. A.)

G. H. Hitchings (U. S. A) 


\begin{tabular}{|c|c|}
\hline AÑO & Física \\
\hline \multirow[t]{3}{*}{1989} & N. F. Ramsey (U. S. A.) \\
\hline & H. G. Dehmelt (U. S. A.) \\
\hline & W. Paul (Alemania) \\
\hline \multirow[t]{3}{*}{1990} & J. I. Friedman (U. S. A.) \\
\hline & H. W. Kendall (U. S. A.) \\
\hline & R. E. Taylor (Canada) \\
\hline 1991 & P. G. de Gennes (Francia) \\
\hline 1992 & G. Charpak (Francia) \\
\hline \multirow[t]{2}{*}{1993} & R. A. Hulse (U. S. A.) \\
\hline & J. H. Taylor Jr. (U. S. A.) \\
\hline \multirow[t]{2}{*}{1994} & B. N. Brockhouse (Canada) \\
\hline & C. G. Shull (U. S. A.) \\
\hline \multirow[t]{2}{*}{1995} & M. L. Perl (U. S. A.) \\
\hline & F. Reines (U. S. A.) \\
\hline \multirow[t]{3}{*}{1996} & D. M. Lee (U. S. A.) \\
\hline & D. D. Osheroff (U. S. A.) \\
\hline & R. C. Richardson (U. S. A.) \\
\hline \multirow[t]{3}{*}{1997} & S. Chu (U. S. A.) \\
\hline & C. Cohen-Tannoudji (Francia) \\
\hline & W. D. Phillips (U. S. A.) \\
\hline \multirow[t]{3}{*}{1998} & R. B. Laughlin (U. S. A.) \\
\hline & H. L. Störmer (Alemania) \\
\hline & D. C. Tsui (U. S. A.) \\
\hline \multirow[t]{2}{*}{1999} & G. Hooft (Holanda) \\
\hline & M. J. G. Veltman (Holanda) \\
\hline \multirow[t]{3}{*}{2000} & Z. I. Alferov (Rusia) \\
\hline & H. Kroemer (Alemania) \\
\hline & J. S. Kilby (U. S. A.) \\
\hline
\end{tabular}

Química

Fisiología y Medicina

S. Altman (Canada) J. M. Bishop (U. S. A.)

T. R. Cech (U. S. A.) H. E. Varmus (U. S. A.)

E. J. Corey (U. S. A.)

J. E. Murray (U. S. A.)

E. D. Thomas (U. S. A.)

R. R. Ernst (Suiza)

R. A. Marcus (U. S. A.)

K. B. Mullis (U. S. A.)

M. Smith (Canada)

G. A. Olah (U. S. A.)

P. J. Crutzen (Paises Bajos)

M. J. Molina (U. S. A.)

F. S. Rowland (U. S. A.)

R. F. Curl Jr. (U. S. A.)

H. W. Kroto (Gran Bretaña)

R. E. Smalley (U. S. A.)

P. D. Boyer (U. S. A.)

J. E. Walker (Gran Bretaña)

J. C. Skou (Dinamarca)

W. Kohn (U. S. A.)

J. A. Pople (U. S. A.)

\section{A. H. Zewail (Egipto)}

A. J. Heeger (U. S. A.)

A. G. MacDiarmid (U. S. A.)

H. Shirakawa (Japón)
E. Neher (Alemania)

B. Sakmann (Alemania)

E. H. Fischer (U. S. A.)

E. G. Krebs (U. S. A.)

R. J. Roberts (U. S. A.)

P. A. Sharp (U. S. A.)

A. G. Gilman (U. S. A.)

M. Rodbell (U. S. A.)

E. B. Lewis (U. S. A.)

C. Nüsslein-Volhard (Alemania)

E. F. Wieschaus (U. S. A.)

P. C. Doherty (Australia)

R. M. Zinkernagel (Suiza)

S. B. Prusiner (U. S. A.)

R. F. Furchgott (U. S. A.)

L. J. Ignarro (U. S. A.)

F. Murad (U. S. A.)

G. Blobel (U. S. A.)

A. Carlsson (Suecia)

P. Greengard (U. S. A.)

E. R. Kandel (U. S. A.) 


\begin{tabular}{|c|c|c|}
\hline 1901 & R. F. A. Sully-Prudhomme (Francia) & $\begin{array}{l}\text { J. H. Dunant (Suiza) } \\
\text { F. Passy (Francia) }\end{array}$ \\
\hline 1902 & C. M. T. Mommsen (Alemania) & $\begin{array}{l}\text { E. Ducommun (Suiza) } \\
\text { C. A. Gobat (Suiza) }\end{array}$ \\
\hline 1903 & B. M. Björnson (Noruega) & W. R. Cremer (Gran Bretaña) \\
\hline 1904 & $\begin{array}{l}\text { F. Mistral (Francia) } \\
\text { J. Echegaray (España) }\end{array}$ & Institut de Droit International (Bélgica) \\
\hline 1905 & H. Sienkiewick (Polonia) & B. von Suttner (Austria) \\
\hline 1906 & G. Carducci (Italia) & T. Roosevelt (U. S. A.) \\
\hline 1907 & R. Kipling (Gran Bretaña) & $\begin{array}{l}\text { E. T. Moneta (Italia) } \\
\text { L. Renault (Francia) }\end{array}$ \\
\hline 1908 & R. C. Eucken (Alemania) & $\begin{array}{l}\text { K. P. Arnoldson (Suecia) } \\
\text { F. Bajer (Dinamarca) }\end{array}$ \\
\hline 1909 & S. O. L. Lagerlöf (Suecia) & $\begin{array}{l}\text { A. M. F. Beernaert (Bélgica) } \\
\text { P. H. B. B. d'Estournelles de Constant } \\
\text { (Francia) }\end{array}$ \\
\hline 1910 & P. J. L. Heyse (Alemania) & International Peace Bureau (Suiza) \\
\hline 1911 & M. Maeterlinck (Bélgica) & $\begin{array}{l}\text { T. M. C. Asser (Holanda) } \\
\text { A. H. Fried (Austria) }\end{array}$ \\
\hline 1912 & G. J. R. Hauptmann (Alemania) & E. Root (U. S. A.) \\
\hline 1913 & R. Tagore (India) & H. La Fontaine (Bélgica) \\
\hline 1914 & No hubo premio & No hubo premio \\
\hline 1915 & R. Rolland (Francia) & No hubo premio \\
\hline 1916 & C. G. V. von Heidenstam (Suecia) & No hubo premio \\
\hline 1917 & $\begin{array}{l}\text { K. Gjellerup (Dinamarca) } \\
\text { H. Pontoppidan (Dinamarca) }\end{array}$ & $\begin{array}{l}\text { Comité Internacional de la Cruz-Roja } \\
\text { (Suiza) }\end{array}$ \\
\hline 1918 & No hubo premio & No hubo premio \\
\hline 1919 & C. F. G. Spitteler (Suiza) & T. W. Wilson (U. S. A.) \\
\hline 1920 & K. P. Hamsun (Noruega) & L. V. A. Bourgeois (Francia) \\
\hline 1921 & A. France (Francia) & $\begin{array}{l}\text { K. H. Branting (Suecia) } \\
\text { C. L. Lange (Noruega) }\end{array}$ \\
\hline
\end{tabular}




\begin{tabular}{|c|c|}
\hline AÑO & Literatura \\
\hline 1922 & J. Benavente (España) \\
\hline 1923 & W. B. Yeats (Irlanda) \\
\hline 1924 & W. S. Reymont (Polonia) \\
\hline 1925 & G. B. Shaw (Gran Bretaña) \\
\hline 1926 & G. Deledda (Italia) \\
\hline 1927 & H. Bergson (Francia) \\
\hline 1928 & S. Undset (Noruega) \\
\hline 1929 & T. Mann (Alemania) \\
\hline 1930 & S. Lewis (U. S. A.) \\
\hline 1931 & E. A. Karlfeldt (Suecia) \\
\hline 1932 & J. Galsworthy (Gran Bretaña) \\
\hline 1933 & I. A. Bunin (Rusia) \\
\hline 1934 & L. Pirandello (Italia) \\
\hline 1935 & No hubo premio \\
\hline 1936 & E. O`Neill (U. S. A.) \\
\hline 1937 & R. M. du Gard (Francia) \\
\hline 1938 & P. S. Buck (U. S. A.) \\
\hline 1939 & F. E. Sillanpää (Finlandia) \\
\hline 1940 & No hubo premio \\
\hline 1941 & No hubo premio \\
\hline 1942 & No hubo premio \\
\hline 1943 & No hubo premio \\
\hline 1944 & J. V. Jensen (Dinamarca) \\
\hline 1945 & G. Mistral (Chile) \\
\hline 1946 & H. Hesse (Suiza) \\
\hline
\end{tabular}

F. Nansen (Noruega)

No hubo premio

No hubo premio

A. Chamberlain (Gran Bretaña)

C. G. Dawes (U. S. A.)

A. Briand (Francia)

G. Stresemann (Alemania)

F. Buisson (Francia)

L. Quidde (Alemania)

No hubo premio

F. B. Kellogg (U. S. A.)

L. O. J. Söderblom (Suecia)

Jane Addams (U. S. A.)

N. M. Butler (U. S. A.)

No hubo premio

N. Angell (Gran Bretaña)

A. Henderson (Gran Bretaña)

C. von Ossietzky (Alemania)

C. S. Lamas (Argentina)

Viscount Cecil of Chelwood (Gran Bretaña)

Comité Nansen para los Refugiados

(U. S. A.)

No hubo premio

No hubo premio

No hubo premio

No hubo premio

No hubo premio

Comité Internacional de la Cruz Roja

(U. S. A.)

C. Hull (U. S. A.)

Emily G. Balch (U. S. A.)

J. R. Mott (U. S. A.) 


$\begin{array}{ll}1947 & \text { A. P. G. Gide (Francia) } \\ 1948 & \text { T. S. Eliot (Gran Bretaña) } \\ 1949 & \text { W. Faulker (U. S. A.) } \\ 1950 & \text { E. Russell (Gran Bretaña) } \\ 1951 & \text { P. F. Lagerkvist (Suecia) } \\ 1952 & \text { F. Mauriac (Francia) } \\ 1953 & \text { W. L. S. Churchill (Gran Bretaña) } \\ 1954 & \text { E. M. Hemingway (U. S. A.) } \\ 1955 & \text { H. K. Laxness (Islandia) } \\ 1956 & \text { J. R. Jiménez (España) } \\ 1957 & \text { A. Camus (Francia) } \\ 1958 & \text { B. L. Pasternak (Rusia) } \\ 1959 & \text { S. Quasimodo (Italia) } \\ 1960 & \text { S. J. Perse (Francia) } \\ 1961 & \text { I. Andric (Yugoslavia) } \\ 1962 & \text { J. Steinbeck (U. S. A.) } \\ 1963 & \text { G. Seferis (Grecia) } \\ & \\ 1964 & \text { J. P. Sartre } \text { (Francia) } \\ 1965 & \text { M. A. Sholokhov (Rusia) } \\ 1966 & \text { S. Y. Agnon (Israel) } \\ 1967 & \text { N. Sachs (Alemania) } \\ \text { M. A. Asturias (Guatemala) } \\ 1968 & \text { Y. Kawabata (Japón) } \\ 1969 & \text { S. Beckett (Francia) } \\ 1970 & \text { A. I. Solzhenitsyn (Rusia) } \\ 1971 & \text { P. Neruda (Chile) }\end{array}$

Friends’ Service Council (Gran Bretaña)

American Friends' Service Committee (U. S. A.)

No hubo premio

Lord Boyd Orr of Brechin (Gran Bretaña)

R. Bunche (U. S. A.)

L. Jouhaux (Francia)

A. Schweitzer (Francia)

G. C. Marshall (U. S. A.)

Office of the United Nations High

Commissioner for Refugees (Naciones Unidas)

No hubo premio

No hubo premio

L. B. Pearson (Canada)

G. Pire (Bélgica)

P. J. Noel-Baker (Gran Bretaña)

A. J. Luthuli (Sur Africa)

D. H. A. C. Hammarskjöld (Suecia)

L. C. Pauling (U. S. A.)

Comité Internacional de la Cruz Roja

Liga de Sociedades de la Cruz Roja (Suiza)

M. L. King Jr. (U. S. A.)

UNICEF (U. S. A.)

No hubo premio

No hubo premio

R. Cassin (Francia)

International Labour Organization (Suiza) R. Frisch (Noruega)

J. Tinbergen (Países Bajos)

N. E. Borlaug (U. S. A.)

J. Tinbergen (Países Bajos)
P. A. Samuelson (U. S. A.)

1971

P. Neruda (Chile)

W. Brandt (Alemania)

S. Kuznets (U. S. A.) 


\begin{tabular}{|c|c|}
\hline AÑO & Literatura \\
\hline 1972 & H. Böll (Alemania) \\
\hline 1973 & P. White (Australia) \\
\hline 1974 & $\begin{array}{l}\text { E. Johnson (Suecia) } \\
\text { H. Martinson (Suecia) }\end{array}$ \\
\hline 1975 & E. Montale (Italia) \\
\hline 1976 & S. Bellow (U. S. A.) \\
\hline 1977 & V. Aleixandre (España) \\
\hline 1978 & I. B. Singer (Polonia) \\
\hline 1979 & O. Elytis (Grecia) \\
\hline 1980 & C. Milosz (Polonia) \\
\hline 1981 & E. Canetti (Gran Bretaña) \\
\hline 1982 & G. G. Marquez (Colombia) \\
\hline 1983 & W. Golding (Gran Bretaña) \\
\hline 1984 & J. Seifert (Checoslovaquia) \\
\hline 1985 & C. Simon (Francia) \\
\hline 1986 & W. Soyinka (Nigeria) \\
\hline 1987 & J. Brodsky (U. S. A.) \\
\hline 1988 & N. Mahfouz (Egipto) \\
\hline
\end{tabular}

Paz

No hubo premio

H. A. Kissinger (U. S. A.)

L. D. Tho (Vietnam del Norte)

S. MacBride (Irlanda)

E. Sato (Japón)

A. D. Sakharov (Rusia)

B. Williams (Irlanda del Norte)

M. Corrigan (Irlanda del Norte)

Amnistía Internacional (Gran Bretaña)

M. A. al-Sadat (Egipto)

M. Begin (Israel)

Madre Teresa de Calcuta (India)

A. P. Esquivel (Argentina)

Office of the United Nations High

Commissioner for Refugees (UNHCR)

A. Myrdal (Suecia)

A. G. Robles (Mexico)

L. Walesa (Polonia)

D. M. Tutu (Suráfrica)

International Physicians for the Prevention of Nuclear

War Inc. (Rusia, U. S. A.)

E. Wiesel (U. S. A.)

O. A. Sanchez (Costa Rica)

United Nations Peace-keeping Forces (Naciones Unidas)
Economía

J. R. Hicks (Gran Bretaña)

K. J. Arrow (U. S. A.)

W. Leontief (U. S. A.)

G. Myrdal (Suecia)

F. A. von Hayek (Austria)

L. V. Kantorovich (Rusia)

T. C. Koopmans (U. S. A.)

M. Friedman (U. S. A.)

B. Ohlin (Suecia)

J. E. Meade (Gran Bretaña)

H. A. Simon (U. S. A.)

T. W. Schultz (U. S. A.)

A. Lewis (U. S. A.)

L. R. Klein (U. S. A.)

J. Tobin (U. S. A.)

G. J. Stigler (U. S. A.)

G. Debreu (U. S. A.)

R. Stone (Gran Bretaña)

F. Modigliani (U. S. A.)

J. M. Buchanan Jr. (U. S. A.)

R. M. Solow (U. S. A.

M. Allais (Francia) 
1989

C. J. Cela (España)

1990

O. Paz (México)

1991

1992

N. Gordimer (Sudáfrica)

D. Walcott (Santa Lucía)

T. Morrison (U. S. A.)

1994

K. Oe (Japón)

1995

S. Heaney (Irlanda)

1996

W. Szymborska (Polonia)

1997

D. Fo (Italia)

1998

J. Saramago (Portugal)

1999

2000

\begin{abstract}
G. Grass (Alemania)
\end{abstract}
G. Xingjian (China)
The 14th Dalai Lama (T. Gyatso) (Tibet) M. S. Gorbachev (Rusia)

\section{A. S. S. Kyi (Birmania)}

R. Menchú Tum (Guatemala)

N. Mandela (Suráfrica)

F. W. de Klerk (Suráfrica)

Y. Arafat (Palestina)

S. Peres (Israel)

Y. Rabin (Israel)

J. Roblat (Gran Bretaña)

C. F. X. Belo (Indonesia)

J. Ramos-Horta (Indonesia)

International Campaign to

Ban Landmines (ICBL)

J. Williams (U. S. A.)

J. Hume (Irlanda)

D. Trimble (Irlanda)

Médicins Sans Frontières (Francia)

K. D. Jung (Corea del Sur)
T. Haavelmo (Noruega)

H. M. Markowitz (U. S. A.)

M. H. Miller (U. S. A.)

W. F. Sharpe (U. S. A.)

R. H. Coase (U. S. A.)

G. S. Becker (U. S. A.)

R. W. Fogel (U. S. A.)

D. C. North (U. S. A.)

J. C. Harsanyi (U. S. A.)

J. F. Nash Jr. (U. S. A.)

R. Selten (Alemania)

R. E. Lucas Jr. (U. S. A.)

J. A. Mirrlees (Gran Bretaña)

W. Vickrey (Canada)

R. C. Merton (U. S. A.)

M. S. Scholes (U. S. A.)

A. Sen (U. S. A.)

R. A. Mundell (U. S. A.)

J. J. Heckman (U. S. A.)

D. L. McFadden (U. S. A.)

|

1 En 1968 el Banco de Suecia instituyó el Premio en Ciencias Económicas en memoria de Alfred Nobel

${ }^{2}$ Rechazó el premio 